\title{
Quantification of selected antidepressants and antipsychotics in clinical samples using chromatographic methods combined with mass spectrometry: A review (2006-2015)
}

\author{
Pavel Sistik ${ }^{a}$, Miroslav Turjap ${ }^{b}$, Andreea Maria lordache ${ }^{a}$, Helena M.E.B. Saldanhaa ${ }^{a}$ Karel Lemr ${ }^{a}$, Petr Bednar ${ }^{a}$
}

\begin{abstract}
Background. Psychiatric disorders contribute significantly to worldwide morbidity and mortality. In the case of depression and schizophrenia, effective drug therapy is available but $30-50 \%$ of patients do not respond sufficiently to the initial treatment regimen. Apart from the development of new molecules, it is desirable to optimize treatment outcomes with agents that are currently available. Therapeutic drug monitoring (TDM) is a suitable and widely accepted approach for improving the efficacy and safety of these drugs.

Methods. A review of the relevant literature published between 2006 and January 2015.

Results and Conclusions. This review describes major advances and drawbacks in the field of chromatography coupled with single or tandem mass spectrometry (LC-MS, LC-MS/MS and GC/MS) of selected antidepressants (agomelatine, vilazodone) and antipsychotics (iloperidone, asenapine, amisulpride, aripiprazole, melperone, zotepine, ziprasidone). The high specificity in combination with high sensitivity makes these techniques an attractive complementary method to traditional procedures used in routine practice for TDM.
\end{abstract}

Key words: antidepressant, antipsychotic, drug, chromatography, mass spectrometry, sample preparation, matrix effect

Received: April 30, 2015; Accepted with revision: December 4, 2015; Available online: January 12, 2016 http://dx.doi.org/10.5507/bp.2015.065

${ }^{a}$ Regional Centre of Advanced Technologies and Materials, Department of Analytical Chemistry, Faculty of Science, Palacky University Olomouc, Czech Republic

${ }^{b}$ Department of Pharmacology and CEITEC, Faculty of Medicine, Masaryk University, Brno, Czech Republic Corresponding author: Petr Bednar, e-mail:petr.bednar@upol.cz

\section{INTRODUCTION}

Antidepressants are probably one of the fastest growing class of drugs. This enormous increase is caused by a variety of interrelated factors. First, there is objective evidence that depressive and mood disorders are far more frequent in recent decades than before. Rising rates of depression, together with other civilization diseases, are related to evolutionary mismatch between past human environments and modern-day living ${ }^{1}$. Second, medical education and the awareness of the population of treatment options for depression have significantly improved in recent years and people are now able to communicate their mental health problems with a doctor more openly than in the past. Third, new antidepressants without (known) side effects are available on the market and prescribed not only by psychiatric specialists but increasingly also by general practitioners ${ }^{2}$. Antipsychotic drug analysis is not only important in psychiatry, but also in sport medicine ${ }^{3}$.

Over the last two decades, many articles have been published on the analysis of antidepressants and antipsychotics by liquid chromatography coupled with mass spectrometry (LC/MS). Reviews of analytical methods for detection of antipsychotic drugs were published by Patteet et al. ${ }^{4}$, Saar et al. ${ }^{5}$ and Zhang et al. ${ }^{6}$. The most recent review, published by Patteet et al. ${ }^{4}$, describes the analysis of antipsychotic drugs in biological matrices between 2010 and September 2014, focusing on advances in sample preparation, analytical techniques and alternative matrices (oral fluid, dried blood spots, hair, nails and other body tissues).

The choice of the proper method for quantitative analysis of trace concentrations of psychotropic drugs and metabolites in biological matrices (e.g. blood, urine, tissue, etc.) is influenced by many variables, including the stability of samples, purity of the material to be injected as well as the required number of compounds for analysis, lower limit of quantitation (LLOQ), chromatographic resolution, mass resolution and throughput of the assay.

This paper provides an overview of analytical methods using a combination of chromatography with mass spectrometry for selected antidepressants (agomelatine, vilazodone) and antipsychotics (iloperidone, asenapine, amisulpride, aripiprazole, melperone, zotepine, ziprasidone) in blood, urine and tissue, published between 2006 and January 2015. In this review, sample preparation, stability issues, chromatographic procedures, identification and quantification by mass spectrometric detection are discussed. 


\section{THERAPEUTIC DRUG MONITORING}

Therapeutic drug monitoring (TDM) can be broadly defined as quantification of serum or plasma concentrations of medications used to optimize drug therapy for individual patients ${ }^{7}$. Over many years, it has proven to be a valuable tool for optimization of therapy with many different types of drugs, such as antibiotics (aminoglycosides, vancomycin), cardiac drugs (digoxin, procainamide/Nacetyprocainamide), antiepileptics, theophylline, lithium and, more recently, immunosupressants, antifungals, anticancer and antiretroviral drugs as well as psychotropics.

TDM should be used reasonably to answer clinically relevant questions and to resolve or anticipate problems in drug therapy management. The benefit of TDM in the case of a particular drug has to be critically evaluated before TDM integration into routine clinical practice ${ }^{8}$. Monitoring of drugs in plasma is most useful if the drug fulfills the following criteria9: a) the relationship between drug concentration and pharmacological response has been reported in pharmacokinetic studies conducted on humans, b) the pharmacological response is not readily and timely assessable, c) the therapeutic range is narrow, d) pharmacokinetic parameters are unpredictable, e) the duration of drug therapy is of a sufficient length, f) the results of the drug assay significantly influence the clinical decision-making process, and g) the drug can be readily measured in the desired biological matrix.

For a considerable number of psychopharmacologic compounds, the quantification of the medications' plasma concentration has become clinical routine for dose adjustment. The benefit of TDM has been proven for tricyclic antidepressants, a number of old and new antipsychotic drugs and for conventional mood stabilizing drugs. In 2011, the TDM expert group of Arbeitsgemeinschaft für Neuropsychopharmakologie und Pharmakopsychiatrie (AGNP) issued "AGNP Consensus Guidelines for Therapeutic Drug Monitoring in Psychiatry: Update 2011 "7. The guidelines defined four levels of recommendation for the utility of TDM in 128 neuropsychiatric drugs: "strongly recommended", "recommended", "useful" and "potentially useful". For the drugs in the "strongly recommended" group, therapeutic reference ranges have been clearly established and routine TDM has been shown to be beneficial. If the plasma concentrations are within the reference range, there is the highest probability of response or remission. At "subtherapeutic" plasma concentrations, the response rate may be similar to placebo under acute treatment, and there is a risk of relapse under chronic treatment. At "supratherapeutic" plasma concentrations, there is a risk of intolerance or intoxication. The "potentially useful" level, on the other hand, indicates for example that plasma concentrations of such drug do not correlate with clinical response (or that the relationship may not have yet been proven) or that dosing of the drug can be easily guided by clinical symptoms, that the drug is not administered on a regular basis, etc. Therefore, TDM of such agents should be restricted to special indications? ${ }^{7}$.

Based on recent evidence, the drugs that are the subject of this paper were assigned the levels "strongly recommended" (amisulpride), "recommended" (aripiprazole, ziprasidone), "useful" (iloperidone, melperone, zotepine) and "potentially useful" (agomelatine, asenapine). Vilazodone is not covered by these guidelines, as this agent was launched on the market after the publication of the guidelines.

\section{PHARMACOLOGICAL PROPERTIES}

Pharmacological and receptor binding properties of psychotropics of interest are briefly outlined below:

Agomelatine (AGO) is an antidepressant with a unique receptor binding profile. It acts as agonist of $\mathrm{MT}_{1}$ and $\mathrm{MT}_{2}$ melatonin receptors, causing a phase advance in circadian rhythm and earlier onset of sleep without influence on sleep architecture. It also acts as an antagonist at serotonin $5-\mathrm{HT}_{2 \mathrm{C}}$ receptors, which increases norepinephrine and dopamine release from neurons of the frontal cortex without affecting extracellular serotonin levels or monoamine reuptake ${ }^{10}$. It may have preferential action in anhedonia. The approved indication is major depressive disorder ${ }^{11}$.

Amisulpride (AMS), a benzamide atypical antipsychotic, was developed prior to full appreciation of the concept of dopamine partial agonism. Thus, it has not been tested in the same preclinical pharmacology systems as newer agents but there are some indications that it may act as a dopamine $\mathrm{D}_{2}$ partial agonist close to the full antagonist end of the $\mathrm{D}_{2}$ spectrum. Amisulpride theoretically blocks presynaptic $\mathrm{D}_{2}$ receptors at low doses and postsynaptic $\mathrm{D}_{2}$ receptors at higher doses. $\mathrm{D}_{2}$ partial agonist activity may theoretically reduce dopamine firing in dopamine overactivity and increase dopamine firing when dopamine concentrations are low. Unlike other atypical antipsychotics, amisulpride does not have potent actions at 5- $\mathrm{HT}_{2 \mathrm{~A}}$ and $5-\mathrm{HT}_{1 \mathrm{~A}}$ receptors. Antagonist actions at 5- $\mathrm{HT}_{7}$ and $5-\mathrm{HT}_{2 \mathrm{~B}}$ may contribute to its antidepressant effects ${ }^{12}$. The approved indication is schizophrenia ${ }^{11}$.

Aripiprazole (ARP), a quinolinone derivative, is an atypical antipsychotic and also mood stabilizer. This agent is a $\mathrm{D}_{2}$ and $\mathrm{D}_{3}$ dopamine and $5-\mathrm{HT}_{1 \mathrm{~A}}$ serotonin partial agonist, which is a major differentiating pharmacologic feature compared to serotonin-dopamine antagonists that are silent antagonists at $\mathrm{D}_{2}$ receptors. Theoretically, aripiprazole reduces dopamine firing in dopamine overactivity (thus improving positive symptoms and mediating antipsychotic actions) and increases dopamine firing when dopamine concentrations are low (thus improving cognitive, negative and mood symptoms). Blockade at $5-\mathrm{HT}_{2 \mathrm{~A}}$ receptors may contribute at clinical doses to causing enhancement of dopamine release in certain brain regions, thus reducing motor side effects and possibly improving cognitive and affective symptoms. Blockade of 5- $\mathrm{HT}_{2 \mathrm{C}}$ and 5- $\mathrm{HT}_{7}$ receptors as well as partial agonist actions at 5-HT $1 \mathrm{~A}$ may contribute to antidepressant actions. Aripiprazole lacks $\mathrm{M}_{1}$ muscarinic and $\mathrm{H}_{1}$ histaminic antagonist properties. The main metabolite dehydro-aripiprazole (DARP) is psychopharmacologically active ${ }^{13}$. Approved indications are schizophrenia, acute mania, agi- 
tation in bipolar disorder and schizophrenia, adjunctive in major depressive disorder (USA, Japan), irritability in autism (USA) (ref. ${ }^{11}$ ).

Asenapine (ASE) is a dibenzo-oxepino pyrrole derivative. It is an atypical antipsychotic and mood stabilizer with mixed $\mathrm{D}_{2} / 5-\mathrm{HT}_{2 \mathrm{~A}}$ antagonist properties. Antagonist actions at dopamine $\mathrm{D}_{2}$ receptors reduce positive symptoms of psychosis and stabilise affective symptoms. Blockade at 5- $\mathrm{HT}_{2 \mathrm{~A}}$ receptors cause enhancement of dopamine release in certain brain regions, thus reducing motor side effects and possibly improving cognitive and affective symptoms. Since the chemical structure of asenapine is related to the antidepressant mirtazapine, asenapine shares some of its pharmacological features. Antagonist actions at $5-\mathrm{HT}_{2 \mathrm{C}}, 5-\mathrm{HT}_{1 \mathrm{~B} / \mathrm{D}}, 5-\mathrm{HT}_{7}$ and $\alpha_{2}$-adrenergic receptors with partial agonist actions at $5-\mathrm{HT}_{1 \mathrm{~A}}$ receptors may contribute to its antidepressant activity ${ }^{14}$. Unlike other antipsychotics, asenapine is given as a sublingual formulation due to very poor bioavailability if administered per os. Approved indications are mania and schizophrenia ${ }^{11}$.

Iloperidone (ILO) is a piperidinyl-benzisoxazole atypical antipsychotic and mood stabilizer. Among atypical antipsychotics, iloperidone has one of the simplest pharmacological profiles and comes closest to the serotonine-dopamine antagonists. Its most distinguishing pharmacological property is its potent $\alpha_{1}$-adrenergic antagonism, which may not only be responsible for the risk of orthostatic hypotension but may also contribute to its low risk of the extrapyramidal syndrome. In addition, moderate $\alpha_{2}$-adrenergic, 5- $\mathrm{HT}_{1 \mathrm{~B} / \mathrm{D}}$ and $5-\mathrm{HT}_{7}$ antagonist and $5-\mathrm{HT}_{1 \mathrm{~A}}$ partial agonist activity suggest potential antidepressant effects ${ }^{13}$. The approved indication is schizophrenia $^{11}$.

Melperone (MLP) is a butyrophenone antipsychotic, licensed as Buronil in many countries. It was first used clinically in the 1960s. This agent shares many pharmacological properties with clozapine, especially high $5-\mathrm{HT}_{2}$ relative to $\mathrm{D}_{2}$ receptor binding affinities. It has low propensity to induce the extrapyramidal syndrome and does not increase plasma prolactin levels. It is potent in blocking $\alpha_{1}$-adrenergic receptors and has weak to no affinity for histaminic $\mathrm{H}_{1}$ and muscarinic receptors ${ }^{15,16}$. In some countries, it is used for the treatment of agitation, anxiety, sleep disturbances, especially in alcohol withdrawal and elderly patients ${ }^{17}$.

Vilazodone (VILA) is an antidepressant from a novel class referred to as SPARI (serotonin partial agonist reuptake inhibitor). It inhibits CNS neuron serotonin reuptake with minimal or no effect on reuptake of norepinephrine or dopamine. Vilazodone also acts as $5-\mathrm{HT}_{1 \mathrm{~A}}$ receptor partial agonist. At presynaptic somatodendritic autoreceptors, this may theoretically enhance serotonergic activity and contribute to its antidepressant action. At postsynaptic receptors, this effect may theoretically diminish sexual dysfunction caused by serotonin reuptake inhibition ${ }^{12}$. The approved indication is major depressive disorder ${ }^{11}$.

Ziprasidone (ZIP) is a benzylisothiazolylpiperazine atypical antipsychotic and also mood stabilizer with mixed $5-\mathrm{HT}_{2 \mathrm{~A}} / \mathrm{D}_{2}$ antagonist activity. Interaction with a myriad of other neurotransmitter receptors may contrib- ute to its efficacy. Specifically, interactions at 5- $\mathrm{HT}_{2 \mathrm{C}}$ and $5-\mathrm{HT}_{1 \mathrm{~A}}$ receptors may contribute to efficacy for cognitive and affective symptoms. Interactions at $5-\mathrm{HT}_{1 \mathrm{D}}$ and $5-\mathrm{HT}_{7}$ receptors and at serotonin and norepinephrine transporters (especially at high doses) may contribute to efficacy for affective symptoms in some patients ${ }^{13}$. Approved indications are schizophrenia, acute mania/mixed mania and adjunctive for the maintenance treatment of bipolar disorder ${ }^{11}$.

Zotepine (ZTP) is an atypical antipsychotic, structurally related to clozapine but with some distinguishing pharmacologic and clinical properties. In addition to its $\mathrm{D}_{2} / 5-\mathrm{HT}_{2 \mathrm{~A}}$ antagonist action, zotepine specifically inhibits norepinephrine reuptake which may have implications for the treatment of both depression and the cognitive symptoms of schizophrenia. 5- $\mathrm{HT}_{2 \mathrm{C}}$ and 5- $\mathrm{HT}_{7}$ antagonist properties also suggest possible efficacy for mood symptoms. Interaction at a myriad of other neurotransmiter receptors may contribute to zotepine 's efficacy and various adverse effects. Metabolite norzotepine is psychopharmacologically active ${ }^{12}$. The approved indication is schizophrenia (Japan) (ref. ${ }^{11}$ ).

Chemical structures of these psychotropics are shown in Fig. 1. Selected pharmacokinetic and TDM characteristics are summarized in Table 1.

\section{SAMPLE PREPARATION}

Since biological samples are often difficult to analyze due to matrix complexity, sample preparation is an essential part of the analytical procedure. Using isolation and/or pre-concentration of analytes with high recovery, this procedure ideally produces clean samples with only low levels of interfering matrix components ${ }^{20}$.

"Quick-and-dirty" sample preparation techniques,
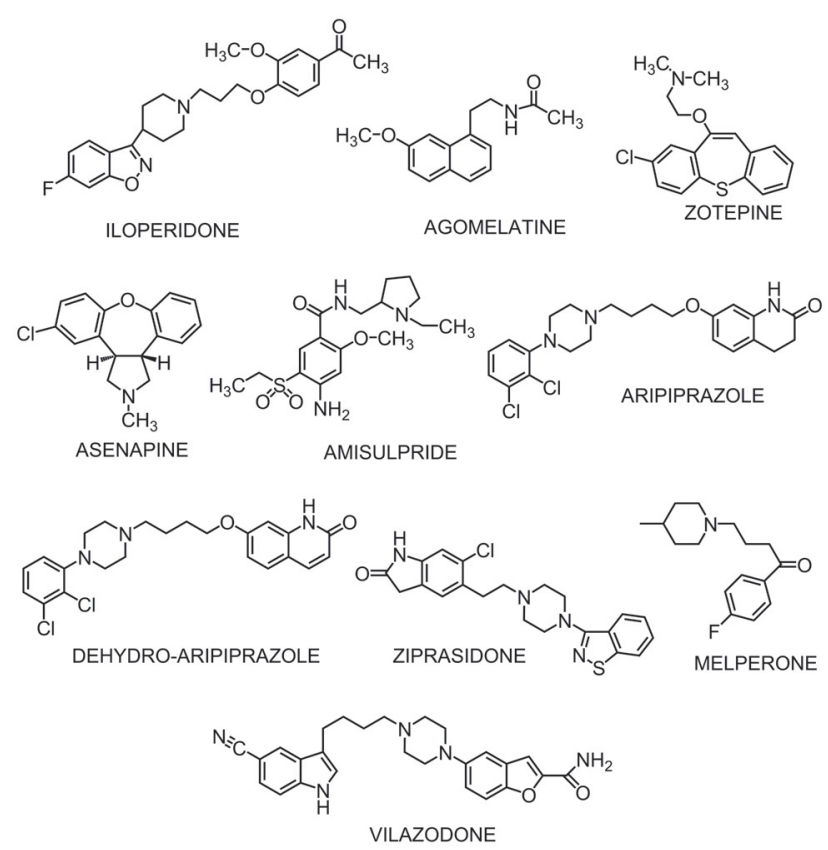

Fig. 1. Structures of selected antidepressants and antipsychotics. 
Table 1. Selected pharmacokinetic and TDM characteristics of the described psychotropics ${ }^{17,7,18,19}$.

\begin{tabular}{|c|c|c|c|c|c|c|}
\hline Drug & Protein binding (\%) & Metabolism & $\begin{array}{l}\text { Elimination } \\
\text { half-life }(\mathrm{h})\end{array}$ & Excretion & $\begin{array}{l}\text { Therapeutic } \\
\text { reference } \\
\text { range } \\
(\mathrm{ng} / \mathrm{mL})^{¥}\end{array}$ & $\begin{array}{l}\text { Laboratory } \\
\text { alert level } \\
(\mathrm{ng} / \mathrm{mL})^{\#}\end{array}$ \\
\hline Agomelatine & 95 & $\begin{array}{l}\text { Hepatic mainly by CYP1A2 and, to a lesser extent, } \\
\text { by CYP2C } 9 \text { and CYP2C } 19 \text {; inactive metabolites; } \\
\text { large/variable first pass effect }\end{array}$ & $1-2$ & Urine ( $80 \%$, as metabolites) & $7-300^{*}$ & 600 \\
\hline Amisulpride & 16 & $\begin{array}{l}\text { Weakly metabolized; } 2 \text { inactive metabolites } \\
\text { identified }\end{array}$ & $\sim 12$ & Urine ( $50 \%$; as unchanged drug) & $100-320$ & 640 \\
\hline Aripiprazole & $\begin{array}{l}>99 \text {, primarily to } \\
\text { albumin }\end{array}$ & $\begin{array}{l}\text { Hepatic via CYP2D6, CYP3A4; active metabolite } \\
\text { dehydro-aripiprazole (represents } 40 \% \text { of the parent } \\
\text { drug exposure in plasma) }\end{array}$ & $\begin{array}{l}\text { Aripiprazole: } 75 \text {; } \\
\text { dehydro-aripiprazole: } 94 \text {; } \\
\text { CYP2D6 poor metabolizers: } \\
\text { Aripiprazole: } 146\end{array}$ & $\begin{array}{l}\text { Feces }(55 \%, \sim 18 \% \text { of the total dose as } \\
\text { unchanged drug); urine }(25 \%,<1 \% \text { of the } \\
\text { total dose as unchanged drug }\end{array}$ & $\begin{array}{c}150-500 \\
\text { (parent drug) }\end{array}$ & 1000 \\
\hline Asenapine & $\begin{array}{l}95 \text { (including } \\
\text { albumin and } \alpha_{1} \text {-acid } \\
\text { glycoprotein) }\end{array}$ & $\begin{array}{l}\text { Hepatic via CYP1A2 oxidation and UGT1A4 } \\
\text { glucuronidation }\end{array}$ & 24 & Urine $(\sim 50 \%)$; feces $(\sim 40 \%)$ & $2-5$ & 10 \\
\hline Iloperidone & $\begin{array}{l}\sim 97 \text { (parent drug); } \\
\sim 92 \text { active } \\
\text { metabolites }\end{array}$ & $\begin{array}{l}\text { Hepatic via CYP2D6 and CYP3A4; active } \\
\text { metabolites (P88 and P95) }\end{array}$ & $18-33$ & $\begin{array}{l}\text { Urine ( } 58 \% \text { extensive metabolizers, } 45 \% \\
\text { poor metabolizers); feces ( } 20 \% \text { extensive } \\
\text { metabolizers, } 22 \% \text { poor metabolizers) }\end{array}$ & $\begin{array}{l}5-10 \\
\text { (parent drug) }\end{array}$ & 20 \\
\hline Melperone & $\sim 32$ & Hepatic; inactive metabolites & $4-6$ & $\begin{array}{l}\text { Mainly by urine (only small amounts } \\
\text { as unchanged drug) }\end{array}$ & $30-100$ & 200 \\
\hline Vilazodone & $\sim 96-99$ & $\begin{array}{l}\text { Extensively hepatic, via CYP3A4 (major pathway) } \\
\text { and 2C19 and 2D6 (minor pathways) }\end{array}$ & $\sim 25$ & $\begin{array}{l}\text { Urine ( } 1 \% \text { as unchanged drug); } \\
\text { feces ( } 2 \% \text { as unchanged drug) }\end{array}$ & $28-63$ & - \\
\hline Ziprasidone & $>99$ & $\begin{array}{l}\text { Extensively hepatic, primarily via non-CYP } \\
\text { pathways; less than one third of total metabolism } \\
\text { via CYP3A4 and CYP1A2 (minor) }\end{array}$ & 6 & $\begin{array}{l}\text { Feces }(\sim 66 \% ;<4 \% \text { of total dose as } \\
\text { unchanged drug); urine }(\sim 20 \% \text {; } \\
<1 \% \text { of total dose as unchanged drug })\end{array}$ & $50-200$ & 400 \\
\hline Zotepine & 97 & $\begin{array}{l}\text { Mainly via CYP3A4 and CYP1A2; active } \\
\text { metabolite norzotepine (represents } 30 \% \text { of the } \\
\text { parent drug exposure in plasma); extensive first } \\
\text { pass metabolism }\end{array}$ & $13-16$ & $\begin{array}{l}\text { Urine }(\sim 40 \%) \text {; feces }(\sim 60 \%) \text { predominantly } \\
\text { as inactive metabolites }\end{array}$ & $\begin{array}{c}10-150 \\
\text { (parent drug) }\end{array}$ & 300 \\
\hline
\end{tabular}

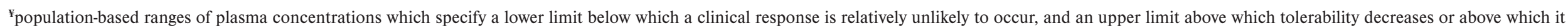
is relatively unlikely that therapeutic improvement may be still enhanced. Samples are collected at the lowest concentration point, i.e. usually before next dose (in $\mathrm{c}_{\text {trough }}$ )

*due to very short half-life, $\mathrm{c}_{\text {trough }}$ is undetectable in plasma; these are plasma levels measured $1-2 \mathrm{~h}$ afer $50 \mathrm{mg}$ dose, i.e. in $\mathrm{c}$

"drug concentrations above the recommended reference range that causes the laboratory to give immediate feedback to the prescribing physician 
such as protein precipitation (PPT) or simple "dilute-andshoot" approaches, can result in serious matrix effects and inherent over-dilution of the analyte ${ }^{21}$.

Liquid-liquid extraction (LLE) or solid phase extraction (SPE) or their combinations are usually applied but these procedures are often laborious and time-consuming. Although sample preparation takes $50-75 \%$ of the total analysis time, most technical innovations of the last five years are related to separation and detection ${ }^{22}$. The development of fast and reliable sample preparation methods is thus greatly required. An ideal sample preparation method should be fast, simple, accurate and precise, and maintain sample integrity while ensuring analyte stability from the sampling till the final measurement ${ }^{23}$.

TDM is usually carried out using plasma, serum or whole blood. Urine is less important, as drug concentration is highly dependent on hydration and the $\mathrm{pH}$ of urine that is used primarily in toxicology ${ }^{24}$. As an alternative to plasma, saliva was tested for TDM of various drugs for painless and non-invasive sampling. However, $\mathrm{pH}$, oral contamination and stimulated and unstimulated ordering can affect the diffusion of the drug from the plasma into the saliva, and a correlation between the concentrations of the drug in the plasma and saliva has to be evaluated. Hairs are useful for forensic and toxicological sciences, as they are stable, easy to handle and can render a history of drug abuse by their segmental analysis ${ }^{25}$.

In clinical practice, conventional TDM is based on venous sampling methods, but dried blood spot (DBS) sampling and analysis is gaining interest nowadays. DBS sampling is considered less painful and time-consuming. DBS samples are of a lower biohazard risk during transportation, which allows easy sampling at home and less expensive transport by normal postal services ${ }^{26}$. Patteet et al. used dried blood spots for quantification of fifteen antipsychotics and seven metabolites with ultra-high performance liquid chromatography/tandem mass spectrometry (UPLC-MS/MS) $\left(\right.$ ref. $\left.^{27}\right)$.

An overview of sample preparation and analytical methods published for selected antidepressants and antipsychotics are shown in Supplementary Table 1. Plasma is here the most common matrix (used in 41 methods), followed by serum, whole blood and urine. Regardless of the used material, the number of monitored analytes influences the demands for the sample preparation method. Most of the published methods have focused on the analysis of one e $^{28-44}$ or less than seven compounds ${ }^{45-54}$. For certain applications, psychotropic drugs are analysed in combination with other pharmaceuticals ${ }^{55,56}$. Several papers focus on multi-analyte methods, often including related metabolites ${ }^{57-65}$ (well-known metabolites such as dehydro-aripiprazole are also active psychotropic compounds). Determination of these metabolites in biological matrices can be useful to develop better therapeutic doses of the parent compound.

Different sample pre-treatments and extraction techniques have been applied for the determination of antidepressants and antipsychotics in whole blood, plasma and urine. For whole blood, extraction can be done either directly from blood ${ }^{56,62,65}$ or by the DBS technique ${ }^{26,27}$.
Plasma can be directly analyzed after protein precipitation $^{32,60,63,66}$ or extracted by SPE (ref. ${ }^{36,40,41,49,51,55,58}$ ) or LLE (ref. ${ }^{28-30,33,34,38,43,44,48,51-54,62}$ ). For the analysis of serum, PPT methods $^{35,50,57}$ or SPE extraction ${ }^{59}$ and LLE extraction ${ }^{64}$ have been used by many authors. In the last several years, sample volume (typically of blood and urine) required for the quantification of antidepressants and antipsychotics has been reduced, due to better analytical instrumentation.

\section{Protein Precipitation}

Determination of free drug concentration is not necessary if therapeutic effect is reflected by more easily measured total drug concentration. This occurs only if the unbound plasma fraction of a drug is the same within and among all patients. If concentration-dependent binding occurs or the unbound plasma fraction of a drug significantly differs from the norm in certain patients (e.g. altered binding capacity and/or affinity of plasma protein for drugs due to certain physiologic or pathophysiologic conditions or drug-induced alterations in binding), the total drug concentration does not reflect the same level of activity. The direct measurement of free form concentration may provide more meaningful information as long as the therapeutic/reference range of free concentration has been established. Drugs highly bound to plasma proteins most likely show wide variations among patients in the unbound plasma fraction and may represent suitable candidates for free concentration monitoring. The results of drug monitoring should be always evaluated with care by experienced clinical pharmacists ${ }^{8}$. Free (unbound) drugs and plasma protein bound drugs can be separated by equilibrium dialysis, ultrafiltration and ultracentrifugation. The characterization of drug-protein interaction is essential for the assessment of the pharmacokinetic implications of binding ${ }^{67}$. Protein precipitation allows release of the protein-bound fraction of the analyte and subsequently measure total drug concentration (i.e. free fraction + bound fraction). Generally, protein precitipation can be done by salts (ammonium sulphate, sodium chloride), metal ions (e.g. $\mathrm{Cu}(\mathrm{II}), \mathrm{Zn}(\mathrm{II})$ and $\mathrm{Fe}(\mathrm{II})$ ), non-ionic polymers (e.g. polyethylene glycol), organic solvents (e.g. acetonitrile, ethanol, acetone), tannic acids, heparin, dextran sulphates, cationic polyelectrolytes (e.g. protamines), short chain fatty acids (e.g. caprylic acid) and trichloroacetic and tungstic acid ${ }^{22}$. The use of increased temperature, $\mathrm{pH}$ or organic solvents can lead to denaturation and should be performed with care to minimize any decrease in yield or activity ${ }^{23}$. Acetonitrile can be considered as a generic medium for protein precipitation of antidepressants. It was used for protein precipitation for determination of amisulpride, asenapine, iloperidone and other psychotropics in human plasma samples ${ }^{63}$ and rat plasma ${ }^{68}$. The ratio of plasma to precipitant $1: 3$ ratio provided recovery between 65 and $96 \%$, except for ASE (46-50\%), with RSD lower than 10\% (ref. ${ }^{63}$ ).

Acidified acetonitrile was applied for PPT of brain tissue samples ${ }^{61}$. Mixtures of solvents (e.g. methanol:acetonitrile mixture $(1: 9, \mathrm{v} / \mathrm{v}))$ also worked well for PPT of ziprasidone and other antidepressants ${ }^{57,60}$. 
Protein precipitation using zinc sulphate for the analysis of antidepressants, antipsychotics and immunosuppressants is often used as well ${ }^{69}$.

Protein precipitation prevents the HPLC column from clogging, ion source contamination and ionization suppression in a mass spectrometer ${ }^{23}$. Protein precipitation and consequent protein removal using centrifugation and/ or filtration is often used as the first (or the only) step of sample preparation. On the other hand, in many more complex cases it must be followed by LLE and SPE procedures.

Generally, protein precipitation has been used successfully to analyze all groups of antipsychotics and antidepressants with recoveries typically exceeding $90 \%\left(\right.$ ref. $^{57}$ ).

\section{Liquid-Liquid Extraction}

LLE utilizing sample distribution between two immiscible liquid organic phases is often used for biological fluid samples (plasma, urine) $\left(\right.$ ref. $\left.^{70}\right)$. The extraction of the drug from the aqueous phase depends mainly on solubility of analyte in the organic solvent (given first of all by polarity) and on $\mathrm{pH}$ of the aqueous phase (driving the ratio of protolytic forms of analyte). To eliminate interferences, back liquid-liquid extraction can be performed. A second extraction procedure with different solvent or $\mathrm{pH}$ of the aqueous phase can also be applied ${ }^{23}$. LLE decreases ion suppression, as salts, proteins and phospolipids display low solubility in the water immiscible solvents ${ }^{70}$. LLE disadvantages consist of time-consuming extraction steps, possible formation of emulsion and health and environmental risks due to some organic solvents ${ }^{71}$. The range of analytes is limited due to required solubility in water immiscible solvents. Solubility and recovery can be improved by addition of a small proportion of more polar solvent but this can increase the amount of endogenous material co-extracted with the analyte.

Although the simple LLE method may not offer ideal $100 \%$ recoveries, it allows good precision and accuracy of measurements ${ }^{34}$. The LLE technique is not suitable for a mixture of analytes with different physicochemical properties. Extraction of bases or acids should be carried out at a $\mathrm{pH}$ two units above or below $\mathrm{pKa}$, respectively ${ }^{23}$.

The selection of extraction solvent is not straightforward. Useful solvents for the selected antidepressants and antipsychotics are mentioned in Supplementary Table 1. The most frequent method involves a $\mathrm{pH}$ adjustment with alkaline media $(\mathrm{pH}>10)$ and subsequent extraction with various ethers, chlorinated solvents (i.e. chloroform, methylene dichloride), ethyl acetate or hexane. The most frequent method involves a $\mathrm{pH}$ adjustment to improve transfer of antipsychotics into organic solvent ${ }^{45,46}$. Zhang reported that addition of $0.5 \mathrm{M} \mathrm{Na}_{2} \mathrm{HPO}_{4}(\mathrm{pH} 10.69)$ to samples prior to liquid-liquid extraction with isopropyl ether, effectively neutralizes the antipsychotics and improves their transfer from plasma to the organic layer ${ }^{46}$. However, the authors found that brain samples required twice the amount of this basic phosphate solution to achieve comparable extraction efficiency to plasma ${ }^{45}$. The efficiency of the LLE, on the other hand, was demonstrated in the paper by Patil et al., who developed a validated method for quantification of agomelatine. During method development, the authors found the extraction efficiency of LLE using ethyl acetate better than the protein precipitation method using acetonitrile and methanol ${ }^{38}$.

\section{Solid Phase Extraction}

Advantages of SPE over LLE include a more efficient separation of interferences from analyte, reduced organic solvent consumption, easier collection of the total analyte fraction, more convenient manual procedures, better removal of particulates and easier automation. On the other hand, LLE systems, unlike solid-phase systems, are more likely to give consistent results year after year, as there is usually less batch to batch variation with solvents compared to SPE sorbents. SPE is more dependent on the nature of the analyte and is thus less suitable for screening of antidepressants with wide structural diversity. In such applications, liquid-liquid extraction may be a more viable solution ${ }^{23}$.

An overview of SPE applications for selected antidepressants and antipsychotics is given in Supplementary Table 1. Six methods applied SPE to plasma ${ }^{36,38,40,41,51,55,58}$, one method to serum ${ }^{59}$, one to brain tissue ${ }^{61}$ and one to human urine ${ }^{49}$. Different retention mechanisms have been applied. Mixed-mode, reversed-phase/strong cationexchange or hydrophilic-lipophilic balance based interactions combined with $\pi-\pi$ and dipole-dipole interactions using various functionalized water-wettable polymeric sorbents represent the most common SPE sorbents used in the area of the studied antidepressants and antipsychotics. These materials provide recovery typically in the range $69-97 \%$ (ref. ${ }^{51}$ ). Unwanted adsorption of some drugs, such as ZIP, onto the surface of plastic tubes and untreated glass tubes represent a problem typical for solid phase extractions. Covering glass tubes with $10 \%(\mathrm{v} / \mathrm{V})$ hexamethyldisilazane in ethyl acetate significantly reduced this adsorption ${ }^{31}$.

\section{STABILITY OF ANALYTES IN BIOLOGICAL SAMPLES}

The instability of small drug molecules in biological fluids can seriously affect the accuracy of results, regardless of the analytical technology used for the bioanalytical assay. The stability of drugs has to be evaluated when developing a new bioanalytical method. Furthermore, stability data are typically collected only as part of method validation and thus, information concerning different storage conditions and data over longer periods of time are often inadequate or completely absent. Drug stability in plasma depends on animal species, time, temperature and $\mathrm{pH}$ (ref. ${ }^{72}$ ). Decomposition of drug molecules in biological samples occurs commonly to a greater extent than a stock solution or purified extract. Instability in biological samples occurs mainly due to enzyme activity. Reduction of the temperature normally slows down not only enzymatic but also spontaneous chemical processes. Long-term plasma storage is possible in the frozen state $^{72}$. 
Suitable choice of $\mathrm{pH}$ can reduce enzymatic as well as non-enzymatic reactions. The addition of a small amount of appropriate buffers such as phosphate, citrate, and bicarbonate into biological samples to maintain an optimum $\mathrm{pH}$ was shown to be an effective way to prevent degradation. Nevertheless, extreme $\mathrm{pH}$ values cause precipitation and degradation of plasma components, and should thus be avoided ${ }^{72,73}$. The addition of antioxidants has been found to be effective in stabilizing some analytes ${ }^{72}$. Fisher et al. ${ }^{75}$ successfully used ascorbic acid to stabilise olanzapine in patient plasma samples. Sample stability is important for transport of samples to the laboratory from other hospitals or laboratories. Our experience and the experiments of other authors ${ }^{36,38,42,44,57,64,65,74,75}$ showed that stability of plasma samples of the studied antidepressants was sufficient for more than $24 \mathrm{~h}$ which is a convenient time to deliver and analyze samples in clinical laboratories.

The analyte is considered stable if the \% change is less than 15, as per US FDA guidelines ${ }^{86}$. In order to determine the stability of drugs in the sample matrix, it is frequently suggested to analyze a set of samples ("control samples") at the beginning of the stability study and an additional set of samples ("stability samples") after a certain time of storage ${ }^{74}$. Stability experiments are often performed at two or three concentration levels: "LOW", "MEDIUM" and "HIGH" (at a low therapeutic concentration, therapeutic concentration and high concentration of the respective drug). Evaluation of the stability of drugs in biological samples is often performed using four different experiments: long-term stability in the sample matrix, freeze/thaw stability, bench-top stability and stability in the prepared samples under conditions of analysis ${ }^{74}$.

Stability studies of ZIP were tested in studies with whole blood $^{74}$, human serum ${ }^{59}$ and human plasma ${ }^{30,36}$. ZIP remained stable in whole blood ${ }^{74}$ specimens when stored at $4{ }^{\circ} \mathrm{C},-20{ }^{\circ} \mathrm{C}$, and $-60{ }^{\circ} \mathrm{C}$ over 9 weeks. However significant degradation was observed when stored at $20{ }^{\circ} \mathrm{C}$, with a loss of almost $100 \%$ after 20 weeks of storage ${ }^{74}$. Stability of human serum ${ }^{59}$ spiked ZIP was evaluated at 3,6 , and 12 months. The difference between old and new spiked serum was less than 15 \pm 2 SEM\% (SEM: standard error of the mean difference) and thus, the stability was acceptable ${ }^{59}$. Quality control plasma samples ${ }^{36}(2,30$ and $360 \mathrm{ng} / \mathrm{mL}$ ) were found to be stable in plasma when placed for $24 \mathrm{~h}$ at $4{ }^{\circ} \mathrm{C}$ and at room temperature. ZIP was stable in the autosampler, furthemore was stable after three freeze/thaw cycles and after storage at $-40{ }^{\circ} \mathrm{C}$ for 30 days $^{36}$. The variations in the concentrations of longterm quality control samples $(4,40,200 \mathrm{ng} / \mathrm{mL})$ analyzed over a period of 6 months were less than $12 \%\left(\right.$ ref. $\left.^{30}\right)$.

The stability issues are well-described in the paper by Patil et al. ${ }^{38}$, who studied human plasma samples of AGO. In this study, agomelatine was stable in autosampler ( $24 \mathrm{~h}$, $10{ }^{\circ} \mathrm{C}$ ), at benchtop ( $12 \mathrm{~h}$ at room temperature), in dry extract $(24 \mathrm{~h})$, for re-injection $(2 \mathrm{~h})$, in third freeze thaw cycle and, finally, in a long-term test (90 days, $-20^{\circ} \mathrm{C}$ ).

Stability experiments of AMS have been performed using human plasma ${ }^{75,29,63}$, haemolysed whole blood ${ }^{63,75}$, oral fluid $^{75}$ and human and calf serum ${ }^{75}$. Amisulpride in tested concentrations $(15,75$ and $250 \mu \mathrm{g} / \mathrm{L})$ was stable in human plasma during 3 freeze-thaw cycles, at ambient temperature for 5 days, at $-20{ }^{\circ} \mathrm{C}$ for 1 year and after 2 years at $-20{ }^{\circ} \mathrm{C}\left(\right.$ ref. $\left.^{75}\right)$. The study of Gschwend et al. ${ }^{29}$ reported a sufficient stability of AMS in plasma and in extracts after sample preparation as in extracts (storage conditions: $<-20{ }^{\circ} \mathrm{C}, 6$ days and $7{ }^{\circ} \mathrm{C}, 6$ days). AMS (in tested concentrations $15,75,250 \mu \mathrm{g} / \mathrm{L}$ ) was stable in the haemolysed whole blood following 3 freeze-thaw cycles, at ambient temperature for 2 days and for 1 week at $2-8{ }^{\circ} \mathrm{C}$ $\left(\right.$ ref. $^{75}$ ). In oral fluid, AMS (tested concentrations 15, 75, $250 \mu \mathrm{g} / \mathrm{L}$ ) was stable after 3 freeze-thaw cycles, 2 days at ambient temperature, 1 week at $2-8{ }^{\circ} \mathrm{C}$, and 2 months at $-20{ }^{\circ} \mathrm{C}\left(\right.$ ref. $\left.^{75}\right)$. In human and calf serum (tested concentrations $15,75,250 \mu \mathrm{g} / \mathrm{L})$, the stability was studied when stored the samples for 5 days at ambient temperature. AMS was stable in these matrices for 4 weeks. AMS was stable when stored at $-20{ }^{\circ} \mathrm{C}$ for 12 months $^{75}$.

Stability of ARP and DARP was investigated in studies with human plasma ${ }^{48,58,75,76}$, haemolysed whole blood ${ }^{75}$, oral fluid and human and calf serum ${ }^{75}$. ARP and DARP in tested concentrations $15,75,250 \mu \mathrm{g} / \mathrm{L}$ were stable in human plasma during 3 freeze-thaw cycles, at ambient temperature for 5 days and at $-20^{\circ} \mathrm{C}$ for 1 year ${ }^{75}$. After 2 years at $-20{ }^{\circ} \mathrm{C}$, only concentration of DARP at high level decreased by about $15 \%$ (ref. ${ }^{75}$ ). ARP and DARP (at the same tested concentrations) were stable in the haemolysed whole blood following 3 freeze-thaw cycles, at ambient temperature for 2 days and for 1 week at $2-8{ }^{\circ} \mathrm{C}$ $\left(\right.$ ref. $\left.^{75}\right)$. In oral fluid, both compounds (tested concentrations $15,75,250 \mu \mathrm{g} / \mathrm{L}$ ) were stable after 3 freeze-thaw cycles, 2 days at ambient temperature, 1 week at $2-8{ }^{\circ} \mathrm{C}$, and 2 months at $-20{ }^{\circ} \mathrm{C}\left(\right.$ ref. $\left.^{75}\right)$. In human and calf serum, ARP was stable for 5 days when stored at ambient temperature (same concentrations as above) (ref. ${ }^{75}$ ). DARP concentration in calf serum decreased by $22 \%$ by day 5 and by $19 \%$ in human serum ${ }^{75}$. When stored at $2-8{ }^{\circ} \mathrm{C}$, DARP concentrations in human serum declined about $18 \%$ at week 3 . ARP was stable in these matrices for 4 weeks at $2-8{ }^{\circ} \mathrm{C}$. After storage at $-20{ }^{\circ} \mathrm{C}$ for 9 months, ARP and DARP concentrations in calf serum decreased by about $18 \%$ and $15 \%$, respectively ${ }^{75}$. In human serum, ARP and DARP concentrations fell by 40 and $31 \%$, respectively. When stored at $2-8{ }^{\circ} \mathrm{C}$ for 6 months, ARP concentration in methanolic solution ${ }^{75}$ declined by $39 \%$. Concentrations of ARP and DARP in methanolic solution fell by $78 \%$ and $75 \%$ respectively, when stored at $-20{ }^{\circ} \mathrm{C}$ for 12 months $^{75}$.

The stability experiments with ASE were performed with human plasma samples ${ }^{51,63}$ and human urine ${ }^{49}$. The stability in human plasma ${ }^{51}$ was determined at two concentrations $(0.075 \mathrm{ng} / \mathrm{mL}$ and $15 \mathrm{ng} / \mathrm{mL})$. ASE was stable after four freeze-thaw cycles and $24 \mathrm{~h}$ at room temperature. Finally, stock solutions in ethanol, when stored below $8{ }^{\circ} \mathrm{C}$, were stable for about 6 months ${ }^{51}$.

ILO was tested for stability in studies with human plasma $^{53,63}$ and human serum ${ }^{64}$. The compound was stable in tested QC samples $(30,300,8000 \mathrm{pg} / \mathrm{mL})$ in human plasma ${ }^{53}$ during 3 freeze-thaw cycles, also $6 \mathrm{~h}$ at room temperature and for 34 days when stored at $-70{ }^{\circ} \mathrm{C}$. 
Processed samples kept in autosampler at $4{ }^{\circ} \mathrm{C}$ were stable for $12 \mathrm{~h}$ (ref. $\left.{ }^{53}\right)$. Stability in human serum ${ }^{64}$ was tested at 2 concentration QC levels (1.5 and $35 \mathrm{ng} / \mathrm{mL}$ ). ILO was stable during 4 freeze-thaw cycles and benchtop stability test (ambient temperature, $3 \mathrm{~h}$ ). After storage at $-20{ }^{\circ} \mathrm{C}$ for 3 months, iloperidone showed a slight decrease in concentration of $13.9 \%$ for low QC while for high QC this decrease was not seen ${ }^{64}$.

To date, no stability studies with zotepine and vilazodone in human samples have appeared in the literature.

\section{SEPARATION TECHNIQUES}

\section{Gas Chromatography}

Gas chromatography (GC) was used for the determination of amine class antidepressants. Since amines are often strongly retained on GC column causing asymmetric peaks, derivatization was applied ${ }^{77}$. Six tricyclic antidepressants were determined by GC with nitrogenphosphorus detection using SPE for sample treatment and promazine as internal standard ${ }^{24}$. Zotepine in human serum or plasma was analyzed by capillary gas-liquid chromatography. LLE with three subsequent extraction steps and nitrogen-phosphorus detector were used $^{78}$.

Huang et al. ${ }^{79}$ proposed a GC-MS method for analysis of ARP and its metabolite in human plasma. $0.5 \mathrm{~mL}$ of plasma was first extracted using SPE column and then derivatized by a mixture of N-Methyl-N-(trimethylsilyl) trifluoroacetamideand (N-trimethylsilylimidazole). The time of chromatographic analysis was more than $15 \mathrm{~min}$. However, most clinical laboratories use liquid chromatography.

\section{Liquid Chromatography}

Although common and well established liquid chromatograpgy (LC) methods for psychotropic drugs have used conventional stationary phases with 3-5 $\mu \mathrm{m}$ particles, the last decade is associated with the advent of sub- $2 \mu \mathrm{m}$ particle stationary phases (ultra-high performance liquid chromatography, UHPLC). Besides the most frequently used reversed phase mode (RP), hydrophilic interaction liquid chromatography (HILIC) also provides utilizable selectivity towards psychotic drugs. A detailed list of the used columns can be found in Supplementary Table 1. For the reversed phase separations, binary gradient elution is commonly used. A weak elution component of mobile phase consists of aqueous solution of an acid (e.g. acetic, formic), ammonium acetate or formate buffer adjusted to appropriate $\mathrm{pH}$ ranging from 3.0-8.1. Acetonitrile and methanol (often with ammonium formate and acetate dissolved in those solvents) represent almost exclusively strong elution components.

In some cases, ion pairing effectively increases retention as demonstrated by Djordjevic Filijovic et al. for aripiprazole and its impurities. In this work, sodium pentanesulfonate was used as ion pairing agent ${ }^{80}$. Ziprasidone and another 12 analytes in human serum were analyzed by a C8 column $(2.0 \times 50 \mathrm{~mm}, 1.8 \mu \mathrm{m})$ in 4 min using gradient elution. Dasandi ${ }^{33}$ and Lei $^{36}$ used a reversed phase UHPLC column for the analysis of ziprasidone. A very fast analysis was reported by Pate $^{41}$ who used a C18 phase with excellent mechanical stability (particles with bridged ethyl-siloxane/silica hybrid structure) for the analysis of aripiprazole in human plasma. Time of LC-MS/ MS analysis with an isocratic elution was only $1.2 \mathrm{~min}$ in this case. It is worth noting that this column allows work throughout almost the entire $\mathrm{pH}$ range, typically from 1 to 12. This permits successful analysis of basic compounds at $\mathrm{pH}$ values far above their $\mathrm{pKa}$ values ${ }^{20}$.

Viette $^{55}$ analysed aripiprazole, amisulpride and another 95 analytes in human plasma. A number of methods have been used for analysis of aripiprazole $\mathrm{e}^{39,40,47,81}$. An UHPLC-MS/MS method was developed for the determination of aripiprazole in human plasma samples with an SPE as sample pretreatment ${ }^{41}$. This method was sensitive, cost-effective and reliable for high throughput bioequivalence study with less than two minutes run time, and showed very good accuracy (less than 3\%). Thirty methods applied HPLC columns while eleven methods applied sub- $2 \mu \mathrm{m}$ particle size columns for the analysis of selected antidepressants and antipsychotics from blood, urine and tissue (see Supplementary Table 1). A very fast separation of quetiapine, perospirone, aripiprazole and quetiapine sulfoxide was achieved using an UHPLC reversed phase column in less than $3 \mathrm{~min}$. The instrumental limit of detection was lower than $0.005 \mu \mathrm{g} / \mathrm{L}$. It is worth noting that high separation efficiency was achieved - peak widths were about 2.5 s. Triple-quadrupole mass spectrometer permitted very high-speed data acquisition without peak parameters degradation ${ }^{47}$. Very useful information about the utilization of ultra high-performance liquid chromatography with photodiode array detection (UHPLC/DAD) in the analysis of a wide range of compounds including antidepressants, benzodiazepines, antipsychotics, antiepileptics and antiparkinsonians is also provided in a recent review by Jiménez Moreno et al. ${ }^{82}$

Simple, fast and reliable methods were also developed on the basis of monolithic materials. Vecchione et al. ${ }^{60}$ published an LC-MS/MS method for the determination of 18 psychotropic drugs including ARP and ZIP in plasma samples using a silica-based reversed phase monolithic column. The overall injection interval was less than 5.5 min. Although not all compounds of interest were mutually resolved by chromatography, the precision and accuracy of the developed $\mathrm{LC} / \mathrm{MS}$ method were adequate for a therapeutic drug monitoring service. Similarly, Kirchherr et al. analyzed forty-eight antidepressants and antipsychotics in human serum using monolithic column ${ }^{57}$.

Core shell particles were also used for the separation of psychotropic drugs. An efficient screening method based on core-shell technology was developed for analysis of agomelatine and another 132 nonsteroidal antiinflammatory drugs, barbiturates, anticonvulsants, antidiabetics, muscle relaxants, diuretics and superwarfarin rodenticide compounds ${ }^{56}$.

Beside reversed phase, the HILIC separation mode has also been successfully applied. Generally, HILIC mode offers better signal of electrospray ionization mass spectrometry (ESI-MS), evaporative light scattering (ELSD) and corona charged aerosol (cCAD) detectors compared to 
RP mode due to utilizable retention of analytes in mobile phases rich in organic solvents ${ }^{83}$. Aripiprazole used as an internal standard was well separated in HILIC separation mode from sigma receptor antagonist CM156 in four minutes, and the limit of MS detection $2 \mu \mathrm{g} / \mathrm{L}$ was achieved ${ }^{39}$.

A method for determination of enantiomers of AMS based on SPE from plasma and HPLC using chiral stationary phase (amylose carbamate coated on silicagel) was developed by Ascalone et al. ${ }^{84}$. The limit of quantitation (LOQ) in human plasma $2.5 \mu \mathrm{g} / \mathrm{L}$ for both S-(-)- and R-(+)-amisulpride enantiomers was achieved. More details are provided in Supplementary Table 1.

\section{MASS SPECTROMETRY}

LC-MS has proven to be a powerful technique in bioanalysis. Various MS detection modes and apparatus were applied for screening of antidepressants and antipsychotics, such as single quadrupole, triple quadrupole, ion trap, TOF analyzer, Orbitrap, FT-ICR, sector instruments and hybrid analysers ${ }^{85}$.

The Food and Drug Administration (FDA) and European Medicines Agency (EMA) provide guidelines for performing bioanalytical method validation, including definition of acceptance criteria for a number of parameters specific to MS (ref. ${ }^{86}$ ).

Triple quadrupole instruments operating in a selected reaction monitoring (SRM) mode are the most common analyzers used in bio-analysis of antidepressants and antipsychotics (Supplementary Table 1).

Electrospray Ionization (ESI) in positive mode is used more often than Atmospheric Pressure Chemical Ionization (APCI) for the quantitation of selected antidepressant and antipsychotics. APCI was applied only in two methods ${ }^{30,62}$ (Supplementary Table 1). ESI and APCI were compared to determine five antidepressants and four atypical antipsychotics and their main metabolites in human serum ${ }^{69}$. The method using ESI was further validated, as it offers a better response in comparison with APCI for all drugs in positive ion mode.

Although simultaneous analysis is very useful for TDM practice and mass spectrometry offers sufficient selectivity, most of the published methods allow quantification of a single compound ${ }^{28-32,34-44}$, sometimes with respective metabolites ${ }^{48-51,53}$. Multi psychotropic drug quantitation methods ${ }^{45-47,55-65}$ include newer antidepressants and antipsychotics recommended for TDM.

Mass spectrometric detection plays an irreplaceable role in the TDM of psychotic drugs. In general, standalone mass spectrometry is not used for TDM of psychotic drugs and LC separation is always used prior to mass spectrometric analysis. Therefore, the following discussion involves LC/MS methods from the point of view of mass spectrometry.

Single quadrupole mass analyzer and electrospray ionization was used for analysis of lurasidone in rat plasma, bile and urine. The detector response was specific and linear in the concentration range $5-5000 \mathrm{ng} / \mathrm{mL}\left(\right.$ ref. ${ }^{37}$ ). A similar approach was adopted for analysis of several psychotropic drugs and their metabolites in TDM. Single ion monitoring mode allowed coverage of the therapeutic range for all the studied psychotropic drugs ${ }^{58}$.

The best results regarding selectivity and sensitivity in the analysis of psychotropic drugs are provided by triple quadrupole mass analysers. Limit of detection for Ziprasidone $0.1 \mathrm{ng} / \mathrm{mL}$ in spiked plasma was achieved using LC/MS with triple quadrupole and electrospray ionization in positive ion mode (Z-spray ion source). This method was validated with good linearity of response in the range of concentrations $0.5-200 \mathrm{ng} / \mathrm{mL}$ and showed high sample throughput ${ }^{28}$. The same ion source was used by Zhang et al., who achieved LLOQ $0.2 \mathrm{ng} / \mathrm{mL}$ for plasma and $0.833 \mathrm{ng} / \mathrm{g}$ for brain tissue and linear response in the concentration range $0.5-200 \mathrm{ng} / \mathrm{mL}$ (ref. ${ }^{31}$ ). Similar results were attained by triple quadrupole mass spectrometer with a TurboIon spray interface. The optimized method provided a lower limit of quantification $0.25 \mathrm{ng} / \mathrm{mL}$ and a linear response in the concentration range $0.25-500$ $\mathrm{ng} / \mathrm{mL}\left(\right.$ ref. $^{30}$ ). A somewhat higher LLOQ $0.7 \mathrm{ng} / \mathrm{mL}$ was achieved by $\mathrm{Lei}^{36}$. In all the methods, the analysis time was less than $3 \mathrm{~min}$. This represents a significant improvement compared to common HPLC/UV-VIS methods with generally much longer times ( $>15 \mathrm{~min}$ ), which is mainly due to a much higher selectivity provided by mass spectrometer. TurboIon source was also used for quantification of ranolazine in human plasma (the method was validated over the concentration range of $5-2000 \mathrm{ng} / \mathrm{mL})\left(\right.$ ref. $\left.^{32}\right)$. A triple quadrupole mass analyzer utilizing travelling wave (T-wave) technology and electrospray was used for analysis of diltiazem. A lower limit of quantification of 0.48 $\mathrm{ng} / \mathrm{mL}$ for dilthiazem and $0.24 \mathrm{ng} / \mathrm{mL}$ for its metabolites was achieved ${ }^{33}$. An almost one order of magnitude lower value of LLOQ was achieved by TurboIon spray/triple quadrupole based method for agomelatine (LLOQ $=0.05$ $\mathrm{ng} / \mathrm{mL})\left(\right.$ ref. $\left.^{38,43}\right)$.

Analysis of amisulpride in plasma was performed using triple quadrupole and electrospray ionization. The clean-up by liquid-liquid extraction using a mixture of diisopropylether and dichloromethane $(1: 1, \mathrm{v} / \mathrm{v})$ was performed to allow selective determination. A limit of detection $0.13 \mathrm{ng} / \mathrm{mL}$ was achieved ${ }^{29}$.

Aripiprazole was analyzed by electrospray (Z-spray)/ triple quadrupole mass spectrometer. Concentration range was linear over $0.5-100 \mathrm{ng} / \mathrm{mL}$ for aripiprazole in plasma and $1.5-300 \mathrm{ng} / \mathrm{g}$ in brain tissue $\mathrm{e}^{40}$. In other studies even lower LLOQ values were achieved, i.e. $0.1 \mathrm{ng} / \mathrm{mL}$ (ref. ${ }^{41}$ ) and $0.05 \mathrm{ng} / \mathrm{mL}$ (ref. ${ }^{48}$ ) with electrospray ionization/triple quadrupole systems. Excellent results were also published by Jia et al. ${ }^{53}$, who achieved LLOQ value $10 \mathrm{pg} /$ $\mathrm{mL}$ for iloperidone in human plasma by a combination of electrospray (TurboIonSpray) with triple quadrupole (Q-TRAP technology).

High scan rate of triple quadrupole systems (dwell time $50 \mathrm{~ms}$ for low level of drug concentrations) allowed simultaneous selected reaction monitoring of 48 antidepresants and antipsychotics (overall range of therapeutic levels: $0.5-2000 \mathrm{ng} / \mathrm{mL}$ ) $\left(\right.$ ref. $\left.^{57}\right)$. Comprehensive data for 13 compounds in a similar system were provided by Hasselstrom $^{59}$. The so-called "scheduled multiple reaction 
monitoring" (timing of MRM transitions during chromatographic run; sMRM) and polarity switching were used for analysis of 17 basic and 1 acid psychotropic drugs ${ }^{60}$. With this method, LLOQ $0.15 \mathrm{ng} / \mathrm{mL}$ for all basic drugs and 15 $\mathrm{ng} / \mathrm{mL}$ for valproic acid (as acid analyte) were obtained. A similar approach, called in the work of Sampedro et al. ${ }^{61}$ "dynamic multiple reaction monitoring" (user-defined MRM time segments and variation of dwell times for each timetable to ensure sufficient number of data points; dMRM), was applied for simultaneous determination of 17 antipsychotic drugs in human brain tissue. Atmospheric pressure chemical ionization as a much less frequent ionization mode was applied for analysis of amisulpride, aripiprazole, dehydro-aripiprazole, clozapine, norclozapine, olanzapine, quetiapine, risperidone, 9-hydroxyrisperidone and sulpiride. Sufficient LLOQ ranged between $1-5 \mathrm{ng} / \mathrm{mL}$ $\left(\right.$ ref. $\left.^{62}\right)$. Ansermont et al. developed a sensitive and selective method for ten psychotropic drugs, where electrospray (Z-spray) and tandem mass spectrometry utilizing travelling wave technology (TQD system) were used. With this system, LLOQ $0.5-1 \mathrm{ng} / \mathrm{mL}$ was achieved for all the tested psychotropic drugs ${ }^{63}$. The paper published by Steuer et al. ${ }^{65}$ compared the potential of two LC/MS platforms, i.e. conventional liquid chromatography coupled to a Q-TRAP mass spectrometer and microflow liquid chromatography coupled to a linear ion trap quadrupole mass spectrometer for analysis of 40 antidepressants and neuroleptics. The two methods provided comparable LODs, LOQs and calibration models. The advantage of microflow system was a low mobile phase consumption, short run time and better separation. However, more stable retention times, more data points per peak and better beta tolerance intervals still make the conventional LC/MS system preferable.

The proper choice of internal standard markedly influences quantitative parameters of analysis. A chemical analogue to the analyzed psychotropic drug is usually used as an internal standard with presumably similar analytical properties $\left(\mathrm{IS}_{\mathrm{ch}}\right)\left(\right.$ ref. $\left.^{87}\right)$. Isotopically labelled analytes $\left(\mathrm{IS}_{\mathrm{il}}\right)$ have become popular in recent decades, utilizing the $\mathrm{m} / \mathrm{z}$ resolution by mass spectrometer. The main drawback of this approach, however, is their price or commercial unavailability but some methods have also appeared in the field of psychotropic drugs. Intra- and inter-day precision reported in some studies focused on one or few analytes fall in the range $0.8-17 \%$ when using IS $_{\mathrm{ch}}$. The precision reported in studies utilizing $\mathrm{IS}_{\mathrm{il}}$ is in the range $0.5-11.5 \%$. Comparing results for aripiprazole as a frequently reported psychotropic drug, the precision of $\mathrm{IS}_{\mathrm{ch}}$ falls in the range $1.1-12.4 \%$ and $\mathrm{IS}_{\mathrm{il}} 0.5-8 \%$. Both comparisons show slightly better precision provided by izotopically labelled standards. However, in studies dealing with multi-analyte screening including metabolites, much higher values were reported (4.4-60.6\%) regardless of whether chemical analogue or labelled compound was used, e.g. ${ }^{65}$.

\section{Potential of Ambient Mass Spectrometry}

LC-MS and LC-MS/MS provide high specificity, accuracy, and precision, but the methods are limited in part by the requirements for sample preparation, which is often time-consuming. Ambient mass spectrometry represent a modern approach allowing fast analysis with virtually no sample pretreatment. Since 2004, more than 40 types of ambient MS methods have been published ${ }^{88}$, differing mainly in ionization mode but few of them are commercially available. Desorption Electrospray Ionization (DESI) and Direct Analysis in Real Time (DART) represent the most routinely used ambient mass spectrometric techniques allowing analysis within seconds ${ }^{89}$. DESI and DART can be applied to characterise both solid materials (e.g. parts of tissues) and liquids. Their main disadvantage is ion suppression or enhancement due to the presence of a complex matrix during measurement ${ }^{90}$. Furthermore, DESI-MS involves a number of geometrical and surface parameters that are critical to maintain an optimum and reproducible signal ${ }^{90}$. Similarly, absolute abundance of ions produced by DART depends on the positioning of the target in the gas stream ${ }^{91}$.

Applications of DESI-MS to detect drugs and metabolites in biological matrices (e.g. blood, urine or hair) have already been reported. Rosting et al. ${ }^{92}$, for instance, developed a DESI-MS/MS method coupled with thin liquid membrane extraction for quantification of drugs in biological fluids (urine, saliva, whole blood). Yao et al. ${ }^{93}$ studied binding of drugs to proteins. To our knowledge, although ambient mass spectrometry is proving to be a particularly powerful approach for analysis of clinical material, it has not been used for analysis of antidepressants and antipsychotics. However, due to rapid recent development, some applications in this area are expected soon. For this reason, the potential of ambient mass spectrometry is briefly mentioned here.

\section{Matrix Effects}

The quantitative analysis of biological samples using a combination of liquid chromatography and mass spectrometry with atmospheric pressure ionization is complicated by the presence of matrix components ${ }^{69}$. Three common methods are applied in matrix effect evaluation: (1) post-column infusion, (2) post-extraction addition and (3) comparison of the slopes of calibration curves ${ }^{33,94,95}$.

The problem can be further complicated by various ion-suppressions due to inter-subject variability and the use of blank bio-matrix with varying lot numbers (i.e. control blood obtained from different patients/subjects) in preparing the calibrators. Differences in ion-suppression between analytes and structurally different internal standards is also often problematic. As already discussed, the use of isotopically labeled internal standards offers sufficient solution ${ }^{73}$. Chin et al. ${ }^{96}$ described the matrix effect of commonly used anticoagulant and lipemia. Sodium heparin and $\mathrm{K}_{3}$ EDTA can complicate determination, which is why serum should be used without these addtives. The matrix effect can also be caused by exogenous substances such as polymers contained in different brands of plastic tubes. Matrix effects related to atmospheric pressure ionization mass spectrometry are comprehensively reviewed by Eeckhaut et al. ${ }^{97}$ and Taylor ${ }^{98}$. 


\section{DISCUSSION}

From the clinical point of view, the drugs that are the subject of this review possess some of the "desired features" for TDM. There is a wide interindividual variability in the pharmacokinetics of these drugs. This may be due to intrinsic factors, such as sex, age, weight, hepatic and renal function, diet, comorbidities and genetic polymorphism of cytochrome P450. The presence of extrinsic factors may further contribute to overall pharmacokinetic variability. For example, non-adherence to oral treatment regimens is common among patients suffering from schizophrenia ${ }^{99}$ and may directly affect treatment outcomes. Further, most of these drugs (with the exception of amisulpride and ziprasidone) are metabolized extensively by cytochrome P450 enzymes and may be therefore subject to significant pharmacokinetic drugdrug interactions ${ }^{100}$. Frequent polypharmacy increases the probability of such interactions. The prevalence of smoking is significantly higher among psychiatric patients (especially among those suffering from schizophrenia) compared to the general population ${ }^{101}$. Smoking induces metabolic activity of CYP1A2; thus, elimination of the substrates of this enzyme as well as clinical response may be significantly affected.

On the other hand, for most of these drugs (with the exception of amisulpride and perhaps aripriprazole and ziprasidone) the plasma concentration - response relationship and therapeutic ranges are not clearly confirmed or are not available at all. For many agents, especially newer ones, the utility of TDM has to be evaluated in prospective pharmacokinetic studies. It is often unclear, for example whether routine TDM of a particular agent could improve the long-term outcomes. Similarly, it is often unclear what the role of active metabolite is and whether it should be measured together with parent drug as an "active moiety" or whether the early steady-state plasma concentrations may be predictive for long-term clinical response in patients suffering from depression/schizophrenia. The latter could be of considerable interest, given the fact that clinical response to antipsychotics and antidepressants is not readily and timely assessable.

Routine TDM of the above drugs is not indicated (with the exception of amisulpride and possibly aripiprazole and ziprasidone), but it may be considered in certain situations in order to a) confirm non-adherence or intoxication b) exclude very low plasma concentrations as a possible reason for suboptimal response/treatment failure c) exclude very high plasma concentrations as a possible reason for poor tolerability/adverse effects d) assess suspected/anticipated pharmacokinetic drug-drug interactions. In certain situations, it may be helpful to measure metabolite plasma concentrations as well (even if pharmacologically inactive) and determine both metabolite/ parent drug concentration ratio and C/D (dose-adjusted plasma concentration). Considering plasma concentrations, and the above values in the context of the data in the guidelines (if available), a patient's previous values and relevant clinical data may substantially increase the clinical utility of TDM.
Regarding analysis itself, clinical laboratories have two main choices in technology for the analysis of drugs in biological fluids: immunoassay or chromatography. Currently, quantitative analysis of drugs for TDM is mainly based on immunoassays (IA), which are suited for a routine laboratory with excellent automation and high throughput. However, there are some well-known drawbacks of this technology, such as potential lack of specificity which may lead to cross-reactivity with metabolites, prodrugs or structurally related compounds ${ }^{102}$. With IA, it is not always possible to measure more stuctures (e.g. parent drug + metabolite) in a single run, which is of special interest, especially in routine TDM labs. Moreover, the analysis costs of IA techniques may be relatively high ${ }^{103}$.

Immunoassays represent useful tools in forensic toxicology for the screening of tricyclic antidepressants ${ }^{104}$. Clinicians need to be aware that the preliminary tests performed by immunoassays are presumptive only and that external factors and variables can influence their results $^{104}$. Another confirmatory test is thus required before making decisions ${ }^{104}$. The application of biochip-based immunoassays to automated analyzers facilitates the integrity, reliability, and accuracy of the drug testing process. This instrumental analytical platform can be applied to the multiplex screening of drugs in different sample matrices. To the best of our knowledge, there are no IA methods published for quantification of the described antidepressants and antipsychotics.

As discussed above, chromatographic and mass spectrometric methods offer high selectivity and reliability for TDM practice and thus represent a viable alternative to routine immunoassays, which offers many advantages. High-performance liquid chromatography coupled with mass spectrometry (HPLC-MS) has been successfully used for several years for quantitative drug analysis in pharmacokinetic studies and TDM and it is now considered a gold standard method. In routine practice, quantification of psychotropics for therapy optimization is almost exclusively performed from venous blood, since this is the only biological fluid with established concentration - clinical response relationship for some of them. In clinical practice, conventional TDM is based on venous sampling methods, but dried blood spot (DBS) sampling and analysis is currently gaining interest. The most important advantages of DBS sampling in TDM are the minimally invasive procedure of a finger prick (home sampling), the small sample volume (children) and the stability of the analyte ${ }^{105}$. Some methods using saliva as a biological matrix has been published, but they are not widespread in routine TDM practice. All psychotropics are probably more or less excreted into breast milk. If a mother is treated with psychotropics and wishes to continue breastfeeding, it may be very helpful to measure breast milk levels in order to estimate the amount of the drug which may be ingested by the baby. Other biological fluids, such as cerebrospinal fluid and urine, are used only in special situations. The blood volume required for TDM of psychotropic drugs depends on the sensitivity of analytical methods. The majority of published methods use different sample volumes. The most often used blood volume for TDM of 
psychotropic drugs falls in the range $100-200 \mu \mathrm{L}$. Since sample collection is uncomfortable for patients, methods requiring only a small amount of biological material for analysis are preferable. However, some authors still report sample volumes larger than $400 \mu \mathrm{L}$ (ref. ${ }^{42,43}$ ).

Serum specimens collected in gel-free tubes are preferred by most TDM laboratories. Plastic gel-barriers and serum separator tubes (SST) should be avoided because they have been found to adsorb many drugs or displace some drugs from their protein binding sites. This aspect appeared to be critical in monitoring of antidepressants and benzodiazepines ${ }^{102}$. Many substances have been documented to interfere with TDM assays. Endogenous matrix components, drug metabolites, decomposition products, concomitant medication, diet components and possibly other exogenous xenobiotics should be mentioned here. Evaluation of the effect of drug interferences is thus an important part of method validation. Psychiatric patients are predominantly treated with combinations of psychotropic drugs or with combinations of psychotropic drugs and antiepileptics. Therefore, the antiepileptic and psychotropic drugs should be tested as potential interfering drugs.

Storage conditions (temperature, length of storage) can significantly influence the stability of selected antidepressants and antipsychotics in biological samples. It is therefore important to be aware of these potential changes when interpreting analytical results ${ }^{74}$. The stability results of most authors confirm that plasma (EDTA anticoagulant) is the sample of choice for TDM of selected antipsychotics and antidepressants. The reason for the observed differences in the stability of a number of analytes among plasma and some of the other matrices studied is unclear ${ }^{75}$. Sample stability is an important issue, especially if the lab also performs analyses for other hospitals, outpatient specialists or laboratories. Sample stability should be sufficient for more than 24 hours, which is a convenient time to deliver and analyze samples in clinical laboratories. After this limit, it is recommended to store the samples in a refrigerator or freezer.

Regardless of the high selectivity and reliability of HPLC/MS, sample preparation remains critical for accuracy of results; therefore, this aspect is described in great detail in this review. Methods using PPT are simple and cheap but produce relatively dirty extracts that may reduce the lifetime of the chromatographic column, extend the cleaning/maintenance of the mass spectrometer or result in matrix effects. LLE and SPE are effective in terms of producing clean extracts and reducing matrix effect but are also laborious and difficult to automate in clinical laboratories, not to mention the fact that they are timeconsuming. As summarized in Supplementary Table 1., LLE remains the most common sample treatment method for analysis of the described antidepressants and antipsychotics from biological matrices. In the last decade, different approaches, such as 96-well microtiter plates, robotic liquid handling stations and supported liquid extraction, have been developed to automate the extraction process but they are uncommon in routine clinical laboratories. As previously estimated, the sample preparation step may take $50-75 \%$ of the total analysis time.
The combination of a sub 2- $\mu \mathrm{m}$ packing material and UHPLC systems has enabled dramatic improvements in chromatographic performance over conventional HPLC, mainly in peak resolution, increased speed and sensitivity. A large number of new stationary phases based on sub-2 $\mu \mathrm{m}$ particles have been developed and used for analysis of psychotropic drugs and their metabolites in human plasma. Regardless of the development of various chromatographic selectivities, modern reversed phase materials still offer the best platform for TDM of the studied psychotropic drugs and analysis of their metabolites. Determination of metabolites in biological matrices can be useful to develop better therapeutic doses of the parent compound. For some agents (aripiprazole, citalopram, olanzapine, sertraline), their active metabolites have not been quantified yet ${ }^{65}$.

Electrospray ionization with tandem mass spectrometer dominates among detectors for LC analysis providing less interference from co-eluting compounds. Tripple quadrupole is the most frequently used MS instrument for analysis of psychotropic drug from human samples. Multiple reaction monitoring (MRM) with at least two reactions monitoring is required by international guidelines. Correct LC/MS analysis is influenced by proper use of a suitable internal standard. This review shows slightly better precision of isotopically labelled standards compared to those based on chemical analogy to the analyzed psychotropic drugs. Isotopically labeled standards are generally recommended by the FDA. In spite of poor commercial availability and high costs, isotopically labelled standards are widespread in routine clinical laboratories.

Ambient mass spectrommetry, especially DESI and DART techniques, are expected to provide a faster alternative for analysis of psychotropic drugs in the near future, although issues connected with stability and reproducibility of signal remain to be solved.

\section{CONCLUSION}

This review summarizes analytical applications of combination of chromatography with mass spectrometry for the analysis of selected antidepressants (agomelatine, vilazodone) and antipsychotics (iloperidone, asenapine, amisulpride, aripiprazole and its metabolite dehydro-aripiprazole, melperone, zotepine, ziprasidone) in blood, urine and tissue, published between 2006 and January 2015. Sample preparation, analyte stability, chromatographic separation and mass spectrometry issues were discussed in detail. Protein precipitation, liquid-liquid extraction and solid phase extraction represent dominant procedures for efficient sample treatment. Pros and cons of each clean-up technique are discussed in depth. For instance, the instability of small drug molecules in biological fluids can seriously affect the accuracy of results. The effects of biological matrix (enzyme activity), temperature and $\mathrm{pH}$ on the stability of analytes are also considered. The results show that enzyme activity is a crucial source of instability and that purified samples are much more stable than crude plasma and tissues. Reduction of tempera- 
ture and suitable control of $\mathrm{pH}$ help to reduce enzymatic as well as non-enzymatic reactions of psychotropic drugs.

The particular advantage of LC-MS/MS methods compared to other techniques is the sensitivity, selectivity and simplicity of the technique. It is evident that LC$\mathrm{MS} / \mathrm{MS}$ is the technique of choice for the quantification of psychotropic drugs and their metabolites in biological matrices. In recent years, there is a trend in clinical and forensic toxicology towards simultaneous quantification of a variety of compounds in one analytical run (multianalyte procedures). However, attention has to be paid to the acceptable analytical parameters of each analyte, since compromise methods are applied in multicomponent screening. A typical modern platform comprises UHPLC chromatography (reversed phase or HILIC stationary phases), electrospray ionization and tandem mass spectrometry based on a triple quadrupole mass analyzer. In most of the reported methods, mass spectrometry was conducted in electrospray ionization mode and quantification limits were in $\mathrm{pg} / \mathrm{mL}$ range.

Acknowledgement: The authors are grateful to RNDr. Hana Brozmanová, CSc. (Department of Clinical Pharmacology, University Hospital, Ostrava) and to assoc. prof. Jan Juřica, Ph.D. (Department of Pharmacology, Faculty of Medicine, Masaryk University, Brno, Czech Republic) for their valuable consultations during the review preparation. The authors acknowledge the financial support from the Ministry of Education, Youth and Sports of the Czech Republic (project LO1305). A.-M.I. and H.M.E.B.S were supported by the Operational Program "Education for Competitiveness" (project CZ.1.07/2.3.00/30.0004 and CZ.1.07/2.3.00/30.0041).

Author contributions: PS, MT, PB: manuscript writing, literature search; AMI, HMEBS: literature search, critical revision; KL: critical revision.

Conflict of interest statement: None declared.

\section{REFERENCES}

1. Hidaka BH, Depression as a disease of modernity: explanations of increasing prevalence. J Affect Disord 2012;140(3):205-14.

2. Mercier A, Auger-Aubin I, Lebeau JP, Schuers M, Boulet P, Van Royen P, Peremans $L$. Why do general practitioners prescribe antidepressants to their patients? A pilot study. Biopsychosoc Med 2014;8:17-25.

3. Smyth WF, Rodriguez V. Recent studies of the electrospray ionisation behaviour of selected drugs and their application in capillary electrophoresis-mass spectrometry and liquid chromatography-mass spectrometry. J Chromatogr A 2007;1159(1-2):159-74.

4. Patteet L, Cappelle D, Maudens KE, Crunelle CL, Sabbe B, Neels H. Advances in detection of antipsychotics in biological matrices. Clin Chim Acta 2015;441(0):11-22.

5. Saar E, Beyer J, Gerostamoulos D, Drummer OH. The analysis of antipsychotic drugs in human matrices using LC-MS(/MS). Drug Test Anal 2012;4(6):376-94.

6. Zhang G, Jr AVT, Bartlett MG. Bioanalytical methods for the determination of antipsychotic drugs. Biomed Chromatogr 2008;22(7):671-87.

7. Hiemke C, Baumann P, Bergemann N, Conca A, Dietmaier O, Egberts K, Fric M, Gerlach M, Greiner C, Grunder G, Haen E, HavemannReinecke $U$, Jaquenoud Sirot E, Kirchherr H, Laux G, Lutz UC, Messer T, Muller MJ, Pfuhlmann B, Rambeck B, Riederer P, Schoppek B, Stingl J, Uhr M, Ulrich S, Waschgler R, Zernig G. AGNP Consensus Guidelines for Therapeutic Drug Monitoring in Psychiatry: Update 2011. Pharmacopsychiatry 2011;44(6):195-235
8. MacKichan JJ. Interpretation of serum drug concentrations. In: Lee M, editor. Basic Skills in Interpreting Laboratory Data. 5 ed. Bethesda: American Society of Health-System Pharmacists; 2013,p.71-117.

9. Ensom MHH, Davis GA, Cropp CD, Ensom RJ. Clinical pharmacokinetics in the 21 st century - Does the evidence support definitive outcomes? Clin Pharmacokinet 1998;34(4):265-79.

10. European Medicines Agency. Assessment Report- Agomelatine: European Medicines Agency; 2013. Available from: http://www. ema.europa.eu/docs/en_GB/document_library/EPAR_-_Public_assessment_report/human/000915/WC500046226.pdf.

11. The ECNP Taskforce on Nomenclature. Neuroscience-based Nomenclature; 2015. Available from: https://www.ecnp.eu/projectsinitiatives/nomenclature.aspx.

12. Stahl SM. Prescriber's Guide: Stahl's Essential Psychopharmacology. 5 ed. New York: Cambridge University Press; 2014.

13. Stahl SM. Stahl's Essential Psychopharmacology: Neuroscientific Basis and Practical Applications. 4 ed. New York: Cambridge University Press; 2013.

14. European Medicines Agency. Assessment report- Asenapine: European Medicines Agency; 2013. Available from: http://www. ema.europa.eu/docs/en_GB/document_library/EPAR_-_Public_assessment_report/human/001177/WC500096898.pdf.

15. Sumiyoshi T, Jayathilake K, Meltzer HY. A comparison of two doses of melperone, an atypical antipsychotic drug, in the treatment of schizophrenia. Schizophrenia Research 2003;62(1-2):65-72.

16. Richelson E, Souder T. Binding of antipsychotic drugs to human brain receptors focus on newer generation compounds. Life Sci 2000;68(1):29-39.

17. SPC BURONIL 25 MG [2015 Jul 14]. Available from: http://www.sukl. cz/modules/medication/search.php.

18. Lexicomp Online (Lexi-Drugs Online): Lexi-Comp, Inc., Hudson, Ohio; [cited 20152015 Jul 7]. Available from: http://online.lexi.com/ (login and subscription required).

19. SPC ZOLEPTIL 50 [2015 Jul 14]. Available from: http://www.sukl.cz/ modules/medication/search.php.

20. Baranowska I, Magiera S, Baranowski J. Clinical applications of fast liquid chromatography: A review on the analysis of cardiovascular drugs and their metabolites. J Chromatogr B 2013;927:54-79.

21. Mullett WM. Determination of drugs in biological fluids by direct injection of samples for liquid-chromatographic analysis. J Biochem Biophys Met 2007;70(2):263-73.

22. Prabu SL, Suriyaprakash TNK. Extraction of Drug from the Biological Matrix: A Review. Applied Biological Engineering - Principles and Practice: InTech; 2012.

23. Korfmacher WA. Using mass spectrometry for drug metabolism studies: CRC Press; 2005.

24. Uřinovská R, Turjap M, Brozmanová H, Grundmann M. Analytical methods for the determination of selected psychopharmaceticals. Ceska Slov Farm 2010;59:103-11.

25. Nakashima K. High-performance liquid chromatographic analysis of drugs of abuse in biologic samples. J Health Sci 2005;51(3):272-7.

26. Berm EJJ, Paardekooper J, Brummel-Mulder E, Hak E, Wilffert B, Maring JG. A simple dried blood spot method for therapeutic drug monitoring of the tricyclic antidepressants amitriptyline, nortriptyline, imipramine, clomipramine, and their active metabolites using LC-MS/MS. Talanta 2015;134(0):165-72.

27. Patteet L, Maudens KE, Stove CP, Lambert WE, Morrens M, Sabbe $B$, Neels $H$. The use of dried blood spots for quantification of 15 antipsychotics and 7 metabolites with ultra-high performance liquid chromatography - tandem mass spectrometry. Drug Test Anal 2015;7(6):502-11. doi: 10.1002/dta.1698.

28. Al-Dirbashi OY, Aboul-Enein HY, Al-Odaib A, Jacob M, Rashed MS. Rapid liquid chromatography-tandem mass spectrometry method for quantification of ziprasidone in human plasma. Biomed Chromatogr 2006;20(4):365-8.

29. Gschwend MH, Arnold P, Ring J, Martin W. Selective and sensitive determination of amisulpride in human plasma by liquid chromatography-tandem mass spectrometry with positive electrospray ionisation and multiple reaction monitoring. J Chromatogr B 2006;831(1-2):132-9.

30. Aravagiri M, Marder SR, Pollock B. Determination of ziprasidone in human plasma by liquid chromatography-electrospray tandem mass spectrometry and its application to plasma level determination in schizophrenia patients. J Chromatogr B 2007;847(2):237-44.

31. Zhang G, Terry AV, Jr., Bartlett MG. Determination of the lipophilic 
antipsychotic drug ziprasidone in rat plasma and brain tissue using liquid chromatography-tandem mass spectrometry. Biomed Chromatogr 2008;22(7):770-8.

32. Bhaumik U, Ghosh A, Sarkar AK, Bose A, Selvan PS, Sengupta P, Chakraborty US, Ghosh D, PalTK. Determination of ranolazine in human plasma by LC-MS/MS and its application in bioequivalence study. J Pharm Biomed Anal 2008;48(5):1404-10.

33. Dasandi B, Shah S, Shivprakash. Development and validation of a high throughput and robust LC-MS/MS with electrospray ionization method for simultaneous quantitation of diltiazem and its two metabolites in human plasma: Application to a bioequivalence study. J Chromatogr B 2009;877(8-9):791-8.

34. Lin SN, Lamm L, Newton TF, Reid MS, Moody DE, Foltz RL. A Liquid Chromatography-Electrospray Ionization-Tandem Mass Spectrometry Method for Quantitation of Aripiprazole in Human Plasma. J Anal Toxicol 2009;33(5):237-42.

35. Nozaki K, Osaka I, Kawasaki H, Arakawa R. Application of on-line electrochemistry/electrospray/tandem mass spectrometry to a quantification method for the antipsychotic drug zotepine in human serum. Anal Sci 2009;25(10):1197-201.

36. Lei YQ, Zhang WY, Li HD, Yan MA, Zhu RH. Determination of Ziprasidone by UPLC-MS-MS and Its Application to a Pharmacokinetic Study of Chinese Schizophrenics. Chromatographia 2010;72(9-10):975-9.

37. Chae YJ, Koo TS, Lee KR. A Sensitive and Selective LC-MS Method for the Determination of Lurasidone in Rat Plasma, Bile, and Urine. Chromatographia 2012;75(19-20):1117-28.

38. Patil SR, Nerurkar KK, Kalamkar AM, Pukale V, Mangaonkar KV Pingale SG. Validated LC-MS/MS method for quantification of agomelatine in human plasma and its application in a pharmacokinetic study. J Mass Spectrom 2012;47(1):23-8.

39. Jamalapuram S, Vuppala PK, Mesangeau C, McCurdy CR, Avery BA. Determination of a highly selective mixed-affinity sigma receptor ligand, in rat plasma by ultra performance liquid chromatography mass spectrometry and its application to a pharmacokinetic study. J Chromatogr B 2012;891-892:1-6.

40. Liang F, Terry AV, Bartlett MG. Determination of aripiprazole in rat plasma and brain using ultra-performance liquid chromatography/electrospray ionization tandem mass spectrometry. Biomed Chromatogr 2012;26(11):1325-32.

41. Patel DP, Sharma P, Sanyal M, Shrivastav PS. SPE-UPLC-MS/MS method for sensitive and rapid determination of aripiprazole in human plasma to support a bioequivalence study. J Chromatogr B 2013;925:20-5.

42. Zeng L-I, Sun L-I, Zou Q, Zhou F, Wei P, Ouyang P-k. Bioavailability comparison of a new form of vilazodone XVII to IV in beagles using liquid chromatography/mass spectrometry. Biomed Chromatogr 2014;28(12):1738-43.

43. Wang XL, Zhang D, Liu M, Zhao HN, Du AH, Meng LJ, Liu HC. LC-MS/ MS method for the determination of agomelatine in human plasma and its application to a pharmacokinetic study. Biomed Chromatogr 2014;28(2):218-22.

44. Sui WW, Yang XJ, Yu WH, Jin Y, Luan XY, Wang XJ, Xu HY. A validated LC-MS/MS method for the rapid quantification of vilazodone in rat plasma: Application to a pharmacokinetic study. J Pharm Biomed Anal 2014;98:228-34.

45. Zhang G, Terry AV, Bartlett MG. Sensitive liquid chromatography/ tandem mass spectrometry method for the simultaneous determination of olanzapine, risperidone, 9-hydroxyrisperidone, clozapine, haloperidol and ziprasidone in rat brain tissue. J Chromatogr $B$ 2007;858(1-2):276-81.

46. Zhang G, Terry AV, Jr., Bartlett MG. Liquid chromatography/tandem mass spectrometry method for the simultaneous determination of olanzapine, risperidone, 9-hydroxyrisperidone, clozapine, haloperidol and ziprasidone in rat plasma. Rapid Commun Mass Spectrom 2007;21(6):920-8.

47. Li KY, Zhou YG, Ren HY, Wang F, Zhang BK, Li HD. Ultra-performance liquid chromatography-tandem mass spectrometry for the determination of atypical antipsychotics and some metabolites in in vitro samples. J Chromatogr B 2007;850(1-2):581-5.

48. Song M, Xu X, Hang T, Wen A, Yang L. Development of an LC-MS/MS method for the simultaneous quantification of aripiprazole and dehydroaripiprazole in human plasma. Anal Biochem 2009;385(2):270-7.

49. de Boer $T$, Meulman E, Meijering $H$, Wieling J, Dogterom $P$, Lass $H$. Development and validation of automated SPE-HPLC-MS/MS meth- ods for the quantification of asenapine, a new antipsychotic agent, and its two major metabolites in human urine. Biomed Chromatogr 2012;26(12):1461-3.

50. Caloro M, Lionetto L, Cuomo I, Simonetti A, Pucci D, De Persis S, Casolla B, Kotzalidis GD, Sciarretta A, De Filippis S, Simmaco M, Girardi P. An improved simple LC-MS/MS method for the measurement of serum aripiprazole and its major metabolite. J Pharm Biomed Anal 2012;62:135-9.

51. de Boer T, Meulman E, Meijering H, Wieling J, Dogterom P, Lass $H$. Quantification of asenapine and three metabolites in human plasma using liquid chromatography-tandem mass spectrometry with automated solid-phase extraction: application to a phase I clinical trial with asenapine in healthy male subjects. Biomed Chromatogr 2012;26(2):156-65.

52. Ambavaram VB, Nandigam V, Vemula M, Kalluru GR, Gajulapalle M. Liquid chromatography-tandem mass spectrometry method for simultaneous quantification of urapidil and aripiprazole in human plasma and its application to human pharmacokinetic study. Biomed Chromatogr 2013;27(7):916-23.

53. Jia MM, Li J, He XM, Liu MZ, Zhou Y, Fan Y, Li WY. Simultaneous determination of iloperidone and its two active metabolites in human plasma by liquid chromatography-tandem mass spectrometry: Application to a pharmacokinetic study. J Chromatogr B 2013;928:52-7.

54. Reddy AVB, Venugopal N, Madhavi G. Simultaneous determination of asenapine and valproic acid in human plasma using LC-MS/MS: Application of the method to support pharmacokinetic study. J Pharm Anal 2013;3(6):394-401.

55. Viette V, Guillarme D, Mylonas R, Mauron Y, Fathi M, Rudaz S, Hochstrasser D, Veuthey JL. A multi-target screening analysis in human plasma using fast liquid chromatography-hybrid tandem mass spectrometry (Part I). Clin Biochem 2011;44(1):32-44.

56. Di Rago M, Saar E, Rodda LN, Turfus S, Kotsos A, Gerostamoulos $\mathrm{D}$, Drummer $\mathrm{OH}$. Fast targeted analysis of 132 acidic and neutral drugs and poisons in whole blood using LC-MS/MS. Forensic Sci Int 2014;243(0):35-43.

57. Kirchherr H, Kuhn-Velten WN. Quantitative determination of fortyeight antidepressants and antipsychotics in human serum by HPLC tandem mass spectrometry: a multi-level, single-sample approach. J Chromatogr B 2006;843(1):100-13.

58. Choong E, Rudaz S, Kottelat A, Guillarme D, Veuthey JL, Eap CB. Therapeutic drug monitoring of seven psychotropic drugs and four metabolites in human plasma by HPLC-MS. J Pharm Biomed Anal 2009;50(5):1000-8.

59. Hasselstrom J. Quantification of antidepressants and antipsychotics in human serum by precipitation and ultra high pressure liquid chromatography-tandem mass spectrometry. J Chromatogr B 2011;879(1):123-8.

60. Vecchione G, Casetta B, Chiapparino A, Bertolino A, Tomaiuolo M, Cappucci F, Gatta R, Margaglione M, Grandone E. A reliable and rapid tool for plasma quantification of 18 psychotropic drugs by ESI tandem mass spectrometry. J Pharm Biomed Anal 2012;67-68:104-13.

61. Sampedro MC, Unceta N, Gomez-Caballero A, Callado LF, Morentin B, Goicolea MA, Meana JJ, Barrio RJ. Screening and quantification of antipsychotic drugs in human brain tissue by liquid chromatography-tandem mass spectrometry: Application to postmortem diagnostics of forensic interest. Forensic Science International 2012;219(1-3):172-80.

62. Fisher DS, Partridge SJ, Handley SA, Couchman L, Morgan PE, Flanagan RJ. LC-MS/MS of some atypical antipsychotics in human plasma, serum, oral fluid and haemolysed whole blood. Forensic Sci Int 2013;229(1-3):145-50.

63. Ansermot N, Brawand-Amey M, Kottelat A, Eap CB. Fast quantification of ten psychotropic drugs and metabolites in human plasma by ultra-high performance liquid chromatography tandem mass spectrometry for therapeutic drug monitoring. J Chromatogr A 2013;1292:160-72.

64. Patteet L, Maudens KE, Sabbe B, Morrens M, De Doncker M, Neels H. High throughput identification and quantification of 16 antipsychotics and 8 major metabolites in serum using ultra-high performance liquid chromatography-tandem mass spectrometry. Clin Chim Acta 2014;429(0):51-8.

65. Steuer AE, Poetzsch M, Koenig M, Tingelhoff E, Staeheli SN, Roemmelt AT, Kraemer T. Comparison of conventional liquid chromatography-tandem mass spectrometry versus microflow liquid 
chromatography-tandem mass spectrometry within the framework of full method validation for simultaneous quantification of 40 antidepressants and neuroleptics in whole blood. J Chromatogr A 2015;1381(0):87-100.

66. Koo TS, Kim SJ, Lee J, Ha DJ, Baek M, Moon H. Quantification of lurasidone, an atypical antipsychotic drug, in rat plasma with high-performance liquid chromatography with tandem mass spectrometry. Biomed Chromatogr 2011;25(12):1389-94.

67. Misl'anova C, Hutta M. Role of biological matrices during the analysis of chiral drugs by liquid chromatography. J Chromatogr B 2003;797(1-2):91-109.

68. Noh K, Jang YJ, Kwon K, Kim E, Jeong TC, Yun H, Kang W. Quantitative determination of amisulpride in rat plasma by HPLC-MS/MS, Arch. Pharm. Res. (2015);38:63-7.

69. Urinovska R, Brozmanova H, Sistik P, Silhan P, Kacirova I, Lemr K, Grundmann M. Liquid chromatography-tandem mass spectrometry method for determination of five antidepressants and four atypical antipsychotics and their main metabolites in human serum. Chromatogr B 2012;907:101-7.

70. Williams L, Merriman S, Lodder H, Howells A, Jordan S, Desbrow C, Cleeve M, Calverley R. High throughput extraction of drugs from biological fluids using an improved supported liquid extraction plate. Book of abstract of TIAFT 2006;247-9.

71. Raikos N, Spagou K, Vlachou M, Pouliopoulos A, Thessalonikeos E, Tsoukali H. Development of a Liquid-Liquid Extraction Procedure for the Analysis of Amphetamine in Biological Specimens by GC-FID. Open Forensic Sci J 2009;2(1):12-5.

72. Chen J, Hsieh Y. Stabilizing drug molecules in biological samples. Ther Drug Monit 2005;27(5):617-24.

73. Bakhtiar R, Majumdar TK. Tracking problems and possible solutions in the quantitative determination of small molecule drugs and metabolites in biological fluids using liquid chromatography-mass spectrometry. J Pharm Tox Met 2007;55(3):227-43.

74. Saar E, Gerostamoulos D, Drummer OH, Beyer J. Assessment of the stability of 30 antipsychotic drugs in stored blood specimens. Forensic Sci Int 2012;215(1-3):152-8.

75. Fisher DS, Partridge SJ, Handley SA, Flanagan RJ. Stability of some atypical antipsychotics in human plasma, haemolysed whole blood oral fluid, human serum and calf serum. Forensic Sci Int 2013;229(13):151-6.

76. Kubo M, Mizooku Y, Hirao Y, Osumi T. Development and validation of an LC-MS/MS method for the quantitative determination of aripiprazole and its main metabolite, OPC-14857, in human plasma. $J$ Chromatogr B 2005;822(1-2):294-9.

77. Fernandes C, Van Hoeck E, Sandra P, Lancas FM. Determination of fluoxetine in plasma by gas chromatography-mass spectrometry using stir bar sorptive extraction. Anal Chim Acta 2008;614(2):201-7.

78. Ulrich S, Meyer FP, Bogerts B. A capillary gas-liquid chromatographic method for the assay of the neuroleptic drug zotepine in human serum or plasma. J Pharm Biomed Anal 1996;14(4):441-9.

79. Huang HC, Liu CH, Lan TH, Hu TM, Chiu HJ, Wu YC, Tseng YL. Detection and quantification of aripiprazole and its metabolite, dehydroaripiprazole, by gas chromatography-mass spectrometry in blood samples of psychiatric patients. J Chromatogr B 2007;856(12):57-61.

80. Djordjevic Filijovic N, Pavlovic A, Nikolic K, Agbaba D. Validation of an HPLC method for determination of aripiprazole and its impurities in pharmaceuticals. Acta Chromatogr 26(1) (2014):13-28.

81. Jamalapuram S, Vuppala PK, Abdelazeem AH, McCurdy CR, Avery BA. Ultra-performance liquid chromatography tandem mass spectrometry method for the determination of AZ66, a sigma receptor ligand, in rat plasma and its application to in vivo pharmacokinetics. Biomed Chromatogr 2013;27(8):1034-40.

82. Moreno AM, Navas MJ, Asuero AG. HPLC-DAD determination of CNSacting drugs in human blood, plasma, and serum. Critical reviews in analytical chemistry / CRC 2014;44(1):68-106.

83. Mitchell CR, Bao Y, Benz NJ, Zhang S. Comparison of the sensitivity of evaporative universal detectors and LC/MS in the HILIC and the reversed-phase HPLC modes. J Chromatogr B 2009;877(32):4133-9.

84. Ascalone V, Ripamonti M, Malavasi B. Stereospecific determination of amisulpride, a new benzamide derivative, in human plasma and urine by automated solid-phase extraction and liquid chroma- tography on a chiral column - Application to pharmacokinetics. J Chromatogr B 1996;676(1):95-105.

85. Maurer $\mathrm{HH}$. What is the future of (ultra) high performance liquid chromatography coupled to low and high resolution mass spectrometry for toxicological drug screening? J Chromatogr A 2013;1292:19-24.

86. Brodie RR, Hill HM. Validation issues arising from the new FDA guidance for industry on bioanalytical method validation. Chromatographia 2002;55(1):S91-4.

87. Bozovic A, Kulasingam V. Quantitative mass spectrometry-based assay development and validation: from small molecules to proteins. Clin Biochem 2013;46(6):444-55.

88. Monge ME, Harris GA, Dwivedi P, Fernandez FM. Mass spectrometry: recent advances in direct open air surface sampling/ionization. Chemical reviews 2013;113(4):2269-308.

89. M WJ, B.C L. Desorption Electrospray Ionization (DESI) Mass Spectrometry: A brief introduction and overview. Current Separations and Drug Development.

90. Morelato M, Beavis A, Kirkbride P, Roux C. Forensic applications of desorption electrospray ionisation mass spectrometry (DESI-MS). Forensic Sci Int 2013;226(1-3):10-21.

91. Cody BR, Laramee JA, Nilles JM, Durst HP. Direct analysis in real time (DART) Mass spectrometry. JEOL news 2005;40(1):8-12.

92. Rosting $\mathrm{C}$, Pedersen-Bjergaard S, Hansen SH, Janfelt C. Highthroughput analysis of drugs in biological fluids by desorption electrospray ionization mass spectrometry coupled with thin liquid membrane extraction. The Analyst 2013;138(20):5965-72.

93. Yao C, Na N, Huang L, He D, Ouyang J. High-throughput detection of drugs binding to proteins using desorption electrospray ionization mass spectrometry. Analytica Chimica Acta 2013;794:60-6.

94. Novakova L. Challenges in the development of bioanalytical liquid chromatography-mass spectrometry method with emphasis on fast analysis. J Chromatogr A 2013;1292:25-37.

95. Chambers E, Wagrowski-Diehl DM, Lu Z, Mazzeo JR. Systematic and comprehensive strategy for reducing matrix effects in LC/MS/MS analyses. J Chromatogr B 2007;852(1-2):22-34.

96. Chin C, Zhang ZP, Karnes HT. A study of matrix effects on an LC/MS/ MS assay for olanzapine and desmethyl olanzapine. J Pharm Biomed Anal 2004;35(5):1149-67.

97. Van Eeckhaut A, Lanckmans K, Sarre S, Smolders I, Michotte Y Validation of bioanalytical LC-MS/MS assays: evaluation of matrix effects. J Chromatogr B 2009;877(23):2198-207.

98. Taylor PJ. Matrix effects: the Achilles heel of quantitative highperformance liquid chromatography-electrospray-tandem mass spectrometry. Clin Biochem 2005;38(4):328-34.

99. Gutierrez-Casares JR, Canas F, Rodriguez-Morales A, Hidalgo-Borrajo $\mathrm{R}$, Alonso-Escolano D. Adherence to Treatment and Therapeutic Strategies in Schizophrenic Patients: The ADHERE Study. CNS Spectr 2010;15(5):327-36.

100.Kennedy WK, Jann MW, Kutscher EC. Clinically significant drug interactions with atypical antipsychotics. CNS Drugs 2013;27(12):1021 48.

101.Poirier MF, Canceil O, Bayle F, Millet B, Bourdel MC, Moatti C, Olie JP, Attar-Levy D. Prevalence of smoking in psychiatric patients. Prog Neuro-Psychopharmacol Biol Psychiatry 2002;26(3):529-37.

102.Llorente Fernandez E, Pares L, Ajuria I, Bandres F, Castanyer B, Campos F, Farre C, Pou L, Queralto JM, To-Figueras J. State of the art in therapeutic drug monitoring. Clinical chemistry and laboratory medicine : CCLM / FESCC 2010;48(4):437-46.

103.Aucella F, Lauriola V, Vecchione G, Tiscia GL, Grandone E. Liquid chromatography-tandem mass spectrometry method as the golden standard for therapeutic drug monitoring in renal transplant. Journal of Pharmaceutical and Biomedical Analysis 2013;86:123-6.

104.Moeller KE, Lee KC, Kissack JC. Urine drug screening: practical guide for clinicians. Mayo Clinic proceedings 2008;83(1):66-76.

105.Wilhelm A, den Burger JG, Swart E. Therapeutic Drug Monitoring by Dried Blood Spot: Progress to Date and Future Directions. Clin Pharmacokinet 2014;53(11):961-73.

\section{Supplemental Material:}

The online version of this article (doi: 10.5507/ bp.2015.065) offers supplementary material. 